\title{
La situación del sector bancario español en el contexto europeo: retos pendientes*
}

\author{
Paula Cruz-García \\ Universitat de València \\ Joaquín Maudos \\ Universitat de València e Ivie
}

\begin{abstract}
Resumen
El objetivo de este artículo es analizar la posición del sector bancario español en el contexto europeo y los cambios que han tenido lugar tras la reestructuración llevada a cabo para corregir los desequilibrios acumulados en la anterior etapa de expansión. Para ello, se analiza la evolución de 2008 a 2016 en variables como la estructura de mercado, modelo de negocio, márgenes, rentabilidad, eficiencia, solvencia, etc. Los resultados muestran que la reestructuración, saneamiento y capitalización han dado sus frutos corrigiendo los problemas del pasado. No obstante, la rentabilidad actual es reducida e insuficiente para atraer al inversor. Ello se debe a factores como las exigencias regulatorias, el elevado volumen de activos improductivos y el entorno de tipos de interés muy reducidos, lo que exige más y nuevas respuestas, sobre todo en tres direcciones: más ajustes en la capacidad instalada, diversificación de la estructura de ingresos y digitalización de la actividad bancaria.
\end{abstract}

Palabras clave: banca española, reestructuración.

Clasificación JEL: G21.

\begin{abstract}
The aim of this paper is to analyse the position of the Spanish banking sector in the European context and the changes that have taken place after the restructuring carried out to correct the imbalances accumulated in the previous expansion period. To this aim, we analyse the evolution of variables such as the market structure, the business model, margins, profitability, efficiency, solvency, etc., during the period 2008-2016. The results show that the restructuring, consolidation and capitalisation have been successful by correcting the problems of the past. However, currently, the profitability is small and insufficient to attract investors. This is due to factors such as the regulatory requirements, the high volume of non-performing assets and the very low interest rate environment, which requires more and new responses, especially in three directions: more adjustments in installed capacity, diversification of the income structure and the digitalisation of the banking activity.
\end{abstract}

Keywords: Spanish banks, restructuring .

JEL classification: G21.

* Los autores agradecen el apoyo financiero del Ministerio de Ciencia e Innovación (proyecto de investigación ECO2013-43959-R). Joaquín Maudos agradece, además, el apoyo financiero de la Generalitat Valenciana (proyecto de investigación PROMETEOII/2014/046). Paula Cruz-García también agradece el apoyo financiero al Ministerio de Educación, Ciencia y Deporte (FPU2014/00936). 


\section{Introducción}

Los recientes informes del BCE (2016) y del FMI (2016) coinciden señalando los factores que explican el principal problema que padece la banca europea: la baja rentabilidad. Un elevado volumen de activos improductivos, mayores exigencias e incertidumbres regulatorias, un entorno de tipos de interés muy reducidos, la creciente competencia bancaria (con la unión bancaria) y no bancaria (la que acompaña a la revolución digital), etc. La combinación de todos estos factores da como resultado un cóctel explosivo en forma de una rentabilidad sobre recursos propios (ROE, por sus iniciales en inglés) insuficiente para atraer al accionista (coste de captar capital). Así, los datos de 2016 para la banca de la Euroárea muestran una ROE del 5,13 por 100 frente a un coste de captar capital entre el 8 por 100 y el 10 por 100 .

El sector bancario español comparte en la actualidad el problema de la baja rentabilidad, aunque con menos intensidad, con la banca europea (ROE del 6,9 por 100), si bien en el negocio doméstico la rentabilidad es inferior. Atrás han quedado las rentabilidades de dos dígitos del periodo de bonanza económica en la que el intenso crecimiento del crédito dio paso a un brusco proceso de desapalancamiento con el pinchazo de la burbuja inmobiliaria y el inicio de la crisis económica en 2008.

Como es ampliamente conocido, la elevada concentración del riesgo en el sector inmobiliario (60 por 100 del crédito en el momento del estallido de la crisis) y los problemas de gobierno corporativo de una parte importante del sector bancario español (las cajas de ahorros) dio paso a un periodo de crisis que ha obligado a corregir los desequilibrios acumulados en el periodo anterior de expansión (exceso de capacidad instalada, elevado gap de liquidez, excesiva dependencia de la financiación mayorista, etc.). El exponencial crecimiento de la tasa de morosidad (incluyendo activos adjudicados) obligó a un saneamiento del activo de tal calibre que en muchas entidades (sobre todo cajas de ahorros) ha sido necesario implementar ayudas públicas y solicitar un rescate (asistencia financiera) con cargo a los fondos europeos. La firma del obligado memorándum de entendimiento (MoU) que acompaña a todo rescate ha definido la hoja de ruta que ha seguido el sector en términos de reestructuración, capitalización y saneamiento.

El mejor exponente de la grave crisis que ha atravesado el sector es el importe del saneamiento que ha sido necesario realizar para absorber las pérdidas del «ladrillo» y que de forma acumulada desde 2008 a 2015, asciende a alrededor de 300.000 millones de euros. Un parte de ese saneamiento ha obligado a implementar ayudas públicas en forma de capital, valoradas en 61.000 millones de euros por el Banco de España (incluyendo aportaciones del FGD). De esa cifra, una parte importante se da por perdida. En concreto, el Tribunal de Cuentas la ha estimado en 41.000 millones de euros.

La información más reciente del sector muestra que la reestructuración ha dado sus frutos corrigiendo los desequilibrios señalados: una reducción del 33 por 100 en el número de oficinas, una caída del 30 por 100 del volumen de empleo, una reducción del gap de liquidez (ratio créditos/depósitos del sector privado) de 0,3 puntos 
porcentuales (hasta el 1,03), un aumento del tamaño medio de la banca (se ha más que cuadruplicado en el caso de las cajas), una mejora de la solvencia, una caída de la tasa de morosidad acompañada de un aumento de su cobertura con provisiones, etc. De esta forma, el sector ha ido poco a poco aumentando su rentabilidad, si bien como se ha señalado el nivel actual no es suficiente para cubrir el coste de captar capital. Además. El crédito (stock) sigue cayendo, aunque más por condiciones de demanda (insuficiente) que de oferta.

A nivel de la banca europea, también la reciente crisis ha obligado a las entidades financieras a reaccionar en muchas dimensiones para hacer el sector viable. Así, aunque con importantes diferencias por países, se ha recurrido a las fusiones para ahorrar costes y ganar eficiencia, disminuyendo el número de bancos. En paralelo, ha aumentado la concentración del mercado. Se han producido cambios en los modelos de negocio, lo que se refleja tanto en la composición de los balances como de la estructura de ingresos. Ha habido ajustes en la capacidad instalada y, de forma generalizada, ha sido necesario aumentar la capitalización para converger a los mayores requerimientos de capital que exige Basilea III. Sin embargo, a pesar de estos cambios, la crisis bancaria está todavía muy presente en varios países, como es el caso de Italia, Alemania y Portugal.

En este contexto, el objetivo de este artículo es hacer balance de la evolución reciente del sector bancario español desde una perspectiva comparada a nivel europeo. Para ello, nos centramos en el periodo 2008-2016 en base a los datos de los grupos bancarios consolidados (incluyendo por tanto el negocio de filiales y sucursales de bancos españoles en el exterior) que ofrece el BCE. La última información disponible en el momento de redactar estas líneas es septiembre de 2016.

El trabajo pasa revista a las distintas dimensiones del negocio bancario, centrando la atención en los cambios que han tenido lugar en los años de crisis: modelo de negocio, estructura de mercado, indicadores estructurales de capacidad, márgenes, rentabilidad, estructura de ingresos, eficiencia, solvencia, calidad del activo, etc. El énfasis siempre se pone en la evolución y situación del sector bancario español en el contexto europeo, sobre todo en comparación con los principales países de la Euroárea.

Además de esta introducción, el trabajo se estructura de la forma siguiente. El apartado 2 se centra en el análisis de los cambios que se han producido en la estructura de mercado de la banca europea (concentración) y en sus indicadores de capacidad (densidad de red, tamaño medio de las oficinas, productividad del trabajo, etc.). En el apartado 3 se analizan los cambios en el modelo de negocio en términos de la estructura del balance de las entidades de crédito. El apartado 4 analiza la liquidez; así como la dependencia de la banca española de la financiación del BCE. El apartado 5 recorre la cuenta de resultados para analizar el impacto de la crisis en los márgenes, la rentabilidad, la eficiencia y la estructura de ingresos. La calidad del activo y la cobertura de los activos problemáticos con provisiones es objeto de análisis en el apartado 6, mientras que la solvencia y la calidad del capital se analizan en el apartado 7. Finalmente, el apartado 8 contiene las conclusiones del trabajo. 


\section{Estructura de mercado e indicadores de capacidad}

Como muestra el Gráfico 1, de 2008 a 2015 se ha reducido un 25 por 100 (1.625 menos) el censo de banco de la Euroárea, ya que ha pasado de 6.359 a 4.734 . En España, la caída casi ha duplicado la media europea (43 por 100), con 155 entidades menos en 2016 (207) que en 2008 (362). Este mayor porcentaje ya refleja la mayor intensidad de la reestructuración de la banca en España, y que se explica sobre todo por las fusiones que han tenido lugar en el antiguo colectivo de las cajas de ahorros. España es el segundo país de la Euroárea con mayor reducción en el número de entidades de crédito desde 2008.

Esta mayor caída en España que en la Euroárea del número de bancos contribuye a explicar el mayor aumento de la concentración del mercado (ver Gráfico 2). Así, en términos de la cuota de mercado de los 5 mayores bancos, el aumento en España multiplica por 4 el de la Euroárea (construida como media ponderada, utilizando como peso el activo de cada país), ya que ha pasado del 42,4 por 100 en 2008 al 60,2 por 100 , mientras que en la Euroárea ha pasado del 44,2 por 100 al 48,8 por 100 . Ha sido tal el aumento de la concentración en España que de situarse por debajo de la media europea en 2008, en 2015 es 11,4 pp. superior. En relación a los principales países europeos, la concentración en España duplica la de Alemania (30,5 por 100) y supera ampliamente la de Francia (47,2 por 100) e Italia (41,1 por 100).

\section{GRÁFICO 1 \\ REDUCCIÓN PORCENTUAL EN EL NÚMERO DE ENTIDADES DE CRÉDITO DE 2008 A 2015}

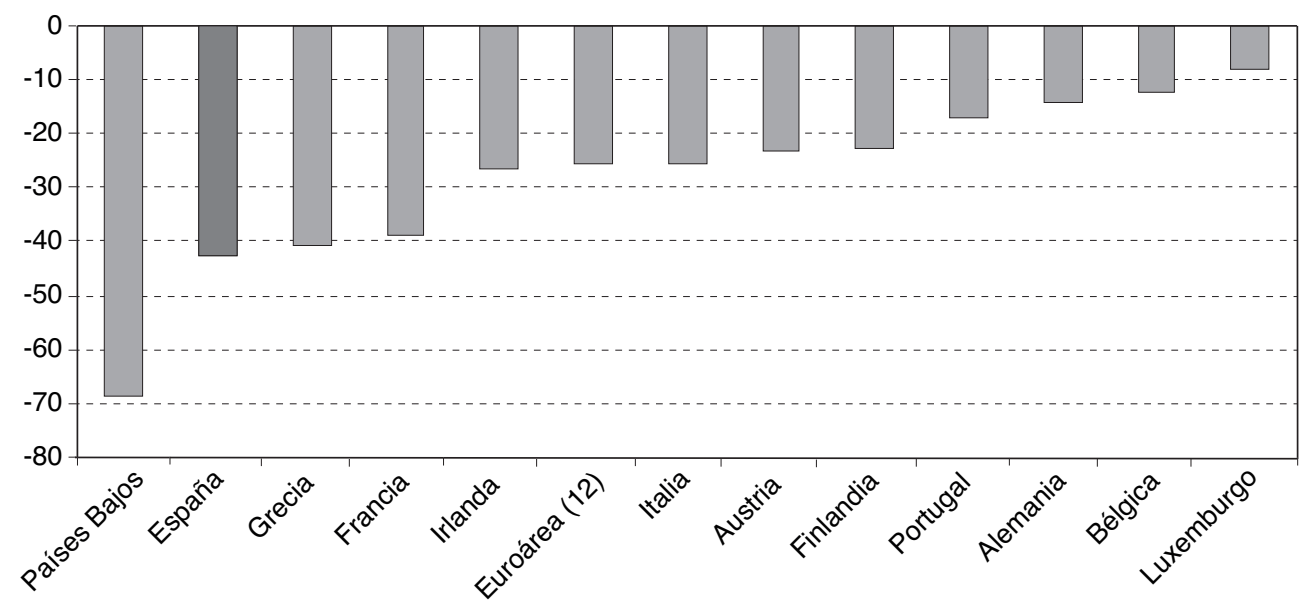

FUENTE: Banco Central Europeo. 


\section{GRÁFICO 2 \\ CONCENTRACIÓN DEL MERCADO BANCARIO}

(a) CR5. Porcentaje

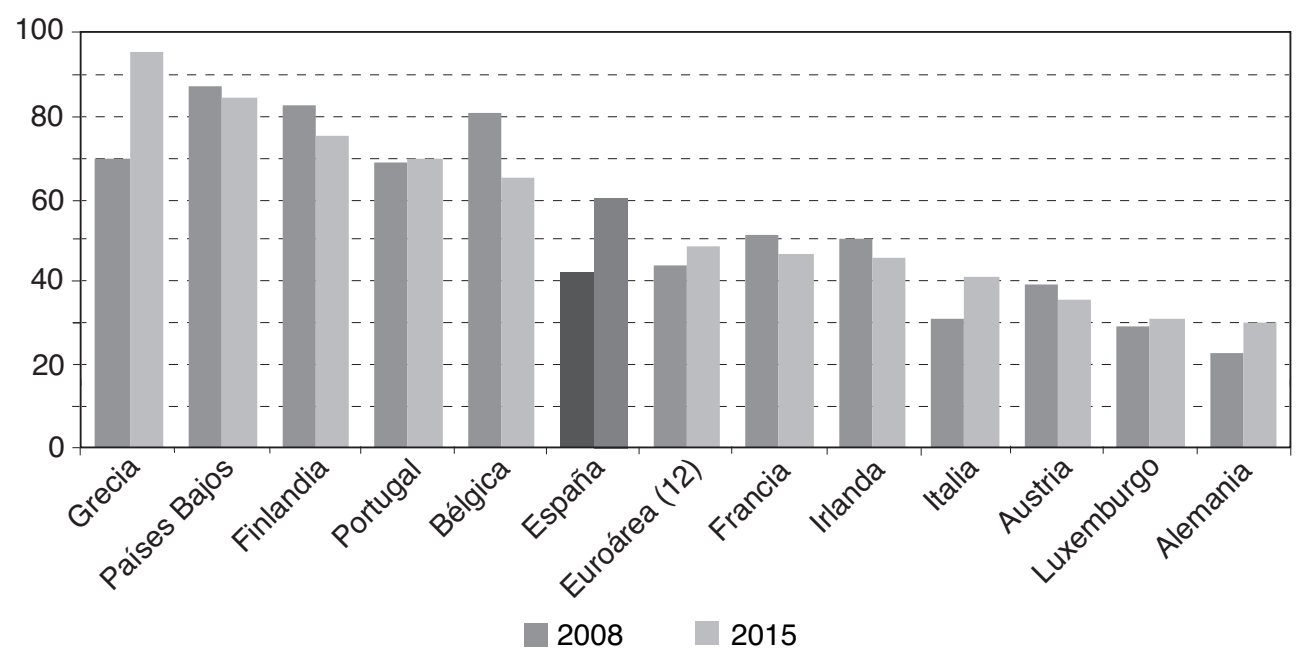

(b) Índice de Herfindahl

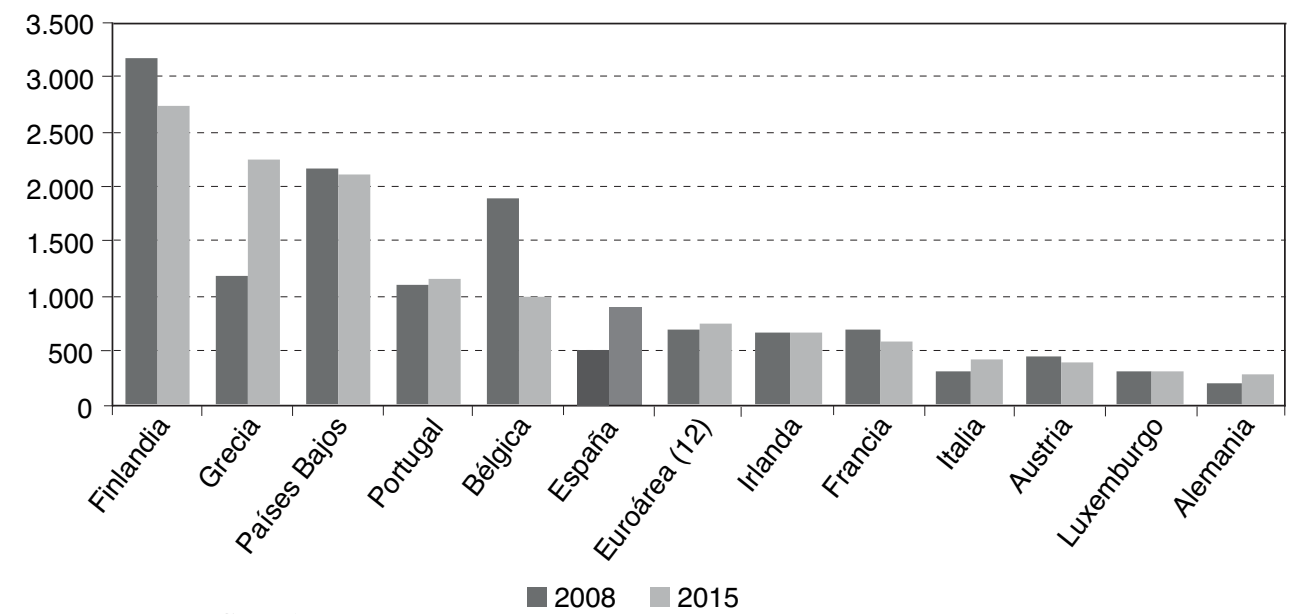

FUENTE: Banco Central Europeo.

Un indicador más riguroso de concentración del mercado es el índice de Herfindahl, que se define como la suma al cuadrado de las cuotas de mercado de todos los bancos de un país. En base a este indicador, la concentración en 2015 también es superior en España (896) que en la Euroárea (747 de media ponderada), habiendo aumentado mucho más (un 80 por 100 de 2008 a 2015). Ha sido tal el aumento de la concentración, que solo un país de la Euroárea (Grecia) supera al crecimiento de España. 
Un indicador que muestra la intensidad del ajuste del exceso de capacidad que tenía la banca española al comienzo de la crisis es el cambio que ha tenido lugar desde 2008 en la densidad de red, aproximada por el número de personas al que atiende por término medio una oficina (Gráfico 3). Así, ha pasado de 1.493 en 2008 a 998 en 2015. No obstante, a pesar de la intensidad del ajuste que se analiza a continuación, España es el segundo país de la Euroárea con mayor densidad de red de oficinas, con una cifra de 998, que es menos de la mitad de la media europea (2.166). En consecuencia, hay margen de maniobra para un mayor ajuste en la red de oficinas en España, teniendo en cuenta que es necesario seguir reduciendo costes en aras a aumentar la eficiencia y, por tanto, la rentabilidad.

La otra cara de la caída de la ratio población/oficina en España es el intenso ajuste en el tamaño de la red que ha caído un 33 por 100 de 2008 a 2015, casi duplicando a la media de la Euroárea, tal y como se puede observar en el Cuadro 1. En concreto, la red de oficinas en España ha pasado de 46.065 en 2008 a 31.087 en 2015, y ha continuado cayendo en 2016 hasta 29.492 (dato de septiembre). En términos absolutos, solo Alemania y Francia tienen más oficinas bancarias que España. En relación a estos países, el ajuste en la red de España ha sido muy superior: 14 por 100 en Alemania y 4,8 por 100 en Francia. En el caso de Italia, que a día de hoy tiene un problema de viabilidad como consecuencia de la alta tasa de morosidad, la reducción de su red desde 2008 ha sido del 10,8 por 100 , por lo que es muy probable que necesite ajustar su capacidad en los próximos años.

\section{GRÁFICO 3}

NÚMERO DE HABITANTES POR OFICINA

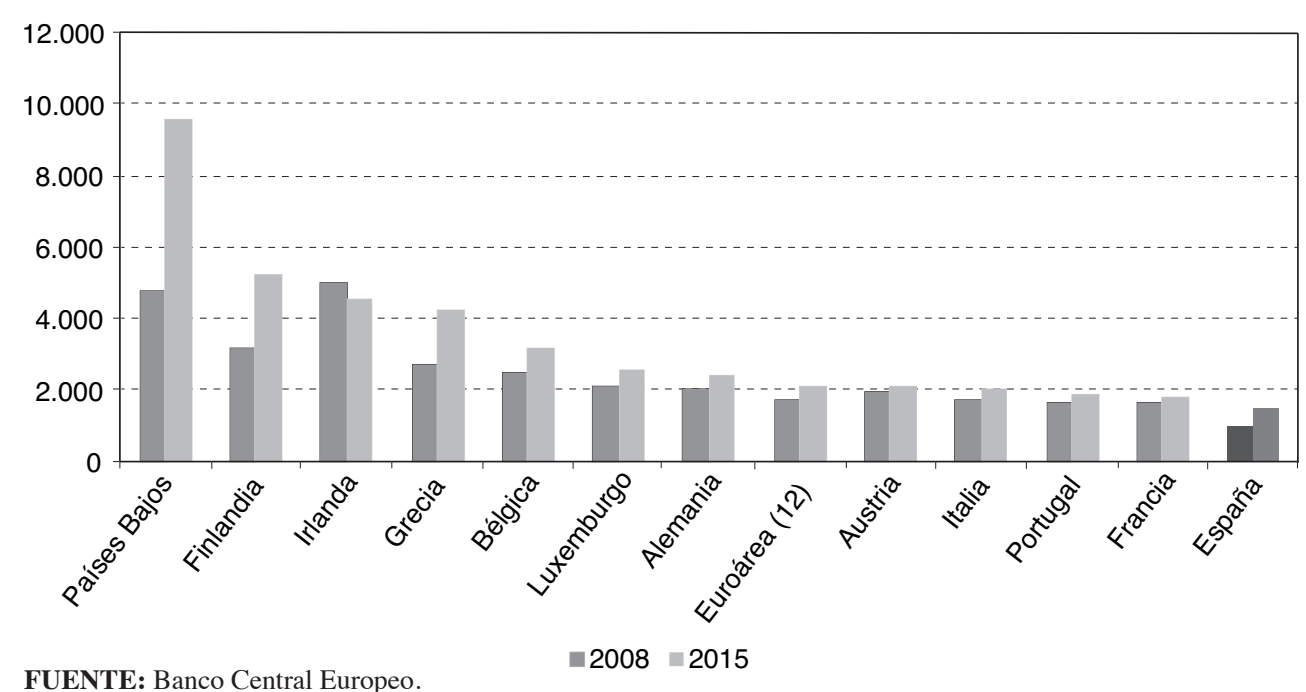

FUENTE: Banco Central Europeo. 
El ajuste de la capacidad instalada también ha tenido lugar con intensidad en España en términos de empleo. En el Cuadro 1 también observamos que de 2008 a 2015 ha caído un 29 por 100, con un valor absoluto cercano a 80.000 personas. En la banca de la Euroárea la caída ha sido menos intensa (un 12 por 100), siendo España uno de los países junto a Grecia e Irlanda donde el ajuste del empleo ha sido mayor. En la práctica generalidad de los países de la Euroárea ha caído el número de trabajadores en banca, siendo la caída reducida en los principales países (5,7 por 100 en Alemania, 4 por 100 en Francia y 12 por 100 en Italia).

Teniendo en cuenta la evolución conjunta de la red de oficinas y el empleo, el tamaño medio de una oficina bancaria apenas ha variado en España en términos de trabajadores por oficina, con una cifra en 2015 de 6,3 (Gráfico 4). España ocupa el último lugar del ranking europeo en esta variable, por lo que de cara al futuro debería acercarse a los mayores valores de la media europea $(12,7)$, lo que conllevaría una ventaja en términos de ganancia de eficiencia y reducción de costes. Además, teniendo en cuenta el imparable avance de la digitalización de las actividades bancarias, a España le queda un largo camino por recorrer reduciendo la red de oficinas e incrementando, en consecuencia, su tamaño medio.

\section{CUADRO 1}

EVOLUCIÓN DE LA RED DE OFICINAS Y EMPLEO

\begin{tabular}{|l|r|r|r|r|r|r|}
\cline { 2 - 7 } \multicolumn{1}{c|}{} & \multicolumn{3}{c|}{ Oficinas } & \multicolumn{3}{c|}{ Empleados } \\
\cline { 2 - 7 } \multicolumn{1}{c|}{} & $\mathbf{2 0 0 8}$ & \multicolumn{1}{c|}{$\mathbf{2 0 1 5}$} & \multicolumn{1}{c|}{$\boldsymbol{\Delta} \%$} & \multicolumn{1}{c|}{$\mathbf{2 0 0 8}$} & \multicolumn{1}{c|}{$\mathbf{2 0 1 5}$} & \multicolumn{1}{c|}{$\boldsymbol{\Delta \%}$} \\
\hline Alemania & 39.531 & 34.045 & $-13,9$ & 685.550 & 646.400 & $-5,7$ \\
\hline Austria & 4.243 & 4.094 & $-3,5$ & 78.754 & 73.315 & $-6,9$ \\
\hline Bélgica & 4.316 & 3.512 & $-18,6$ & 65.985 & 55.783 & $-15,5$ \\
\hline España & 46.065 & 31.087 & $-32,5$ & 276.497 & 196.553 & $-28,9$ \\
\hline Finlandia & 1.672 & 1.051 & $-37,1$ & 25.699 & 21.806 & $-15,1$ \\
\hline Francia & 39.467 & 37.567 & $-4,8$ & 424.536 & 407.645 & $-4,0$ \\
\hline Grecia & 4.097 & 2.543 & $-37,9$ & 66.165 & 46.086 & $-30,3$ \\
\hline Irlanda & 895 & 1.029 & 15,0 & 40.507 & 27.091 & $-33,1$ \\
\hline Italia & 34.169 & 30.475 & $-10,8$ & 338.035 & 298.575 & $-11,7$ \\
\hline Luxemburgo & 230 & 223 & $-3,0$ & 27.208 & 25.980 & $-4,5$ \\
\hline Países Bajos & 3.421 & 1.764 & $-48,4$ & 116.000 & 90.137 & $-22,3$ \\
\hline Portugal & 6.417 & 5.598 & $-12,8$ & 62.377 & 52.496 & $-15,8$ \\
\hline Euroárea (12) & 184.523 & 152.988 & $-17,1$ & 2.207 .313 & 1.941 .867 & $-12,0$ \\
\hline
\end{tabular}

FUENTE: Banco Central Europeo. 


\section{GRÁFICO 4 \\ NÚMERO DE EMPLEADOS POR OFICINA}

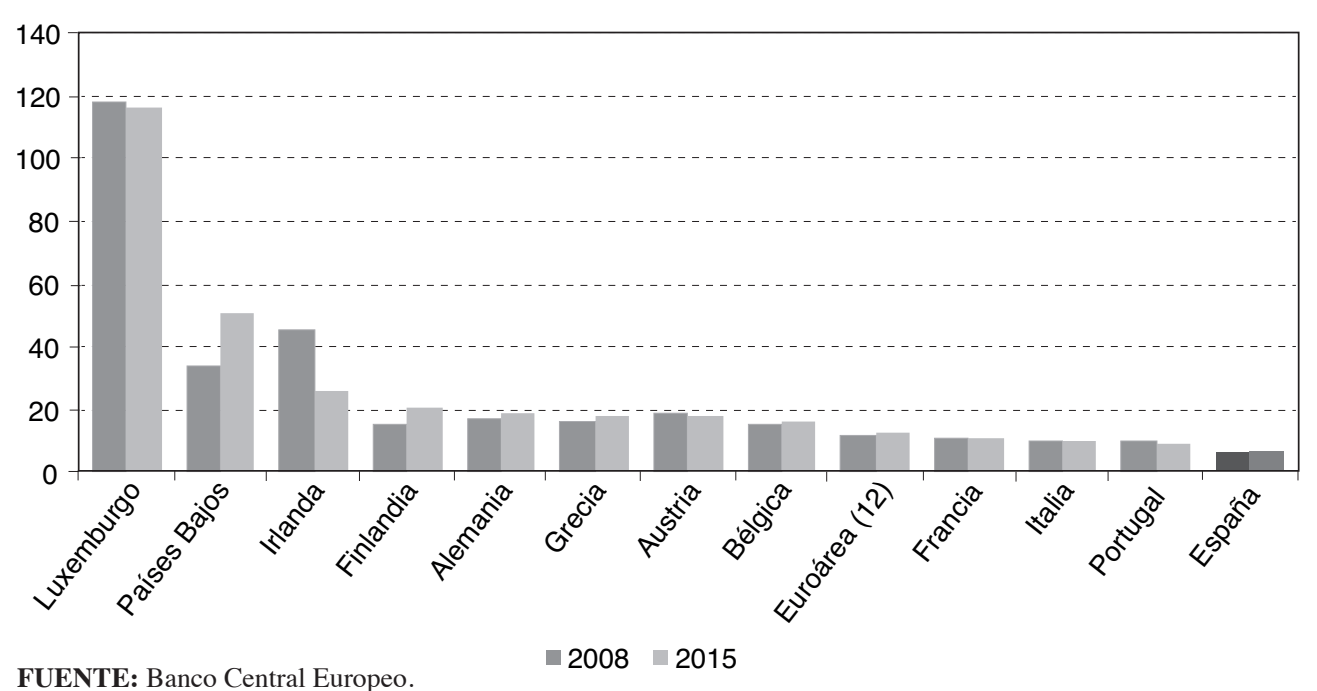

\section{Especialización y modelo de negocio}

Como consecuencia de la crisis financiera que estalló en 2008, se han producido importantes cambios en la composición del balance de las entidades bancarias. Tal y como se puede observar en el Cuadro 2 (págs. 90 y 91), en el promedio de la Euroárea y especialmente en España, estamos ante una banca de intermediación tradicional, donde los créditos y los depósitos al sector privado no financiero son la base del negocio.

Pese a haberse reducido la diferencia de 2008 a 2016, España tiene un carácter de banca al por menor más acusado que la Euroárea. En 2008, los créditos al sector privado no financiero suponían el 55,64 por 100 del balance, siendo un 33,85 por 100 en el caso de la media de la Euroárea. Sin embargo, en 2016 esta partida ocupa un 46,96 por 100 del balance en España, mientras que en la Euroárea un 34,80 por 100. Esta convergencia se debe, en gran medida, a la caída del crédito que ha tenido lugar en España. Si observamos la especialización del activo (Gráfico 5) se puede apreciar también el carácter retail, tanto de la banca española como de la Euroárea.

Por el lado del pasivo, la diferencia con respecto a la banca de la Euroárea en el peso de los depósitos al sector privado no financiero también se ha reducido, pasando de 18,13 por 100 en 2008 a 15,03 por 100 en 2016. También cabe destacar el incremento de la importancia de los recursos propios. Pese a que dicho incremento se ha dado tanto en España como en la Euroárea, ha sido superior en España (3,87 pp. frente a 2,49 ) debido al esfuerzo realizado por el sector bancario español en materia de capitalización. Si observamos la especialización del pasivo (Gráfico 6), se aprecia también este esfuerzo en capitalización. 


\section{GRÁFICO 5}

DISTRIBUCIÓN PORCENTUAL DEL ACTIVO DE LAS INSTITUCIONES FINANCIERAS MONETARIAS

(a) 2008

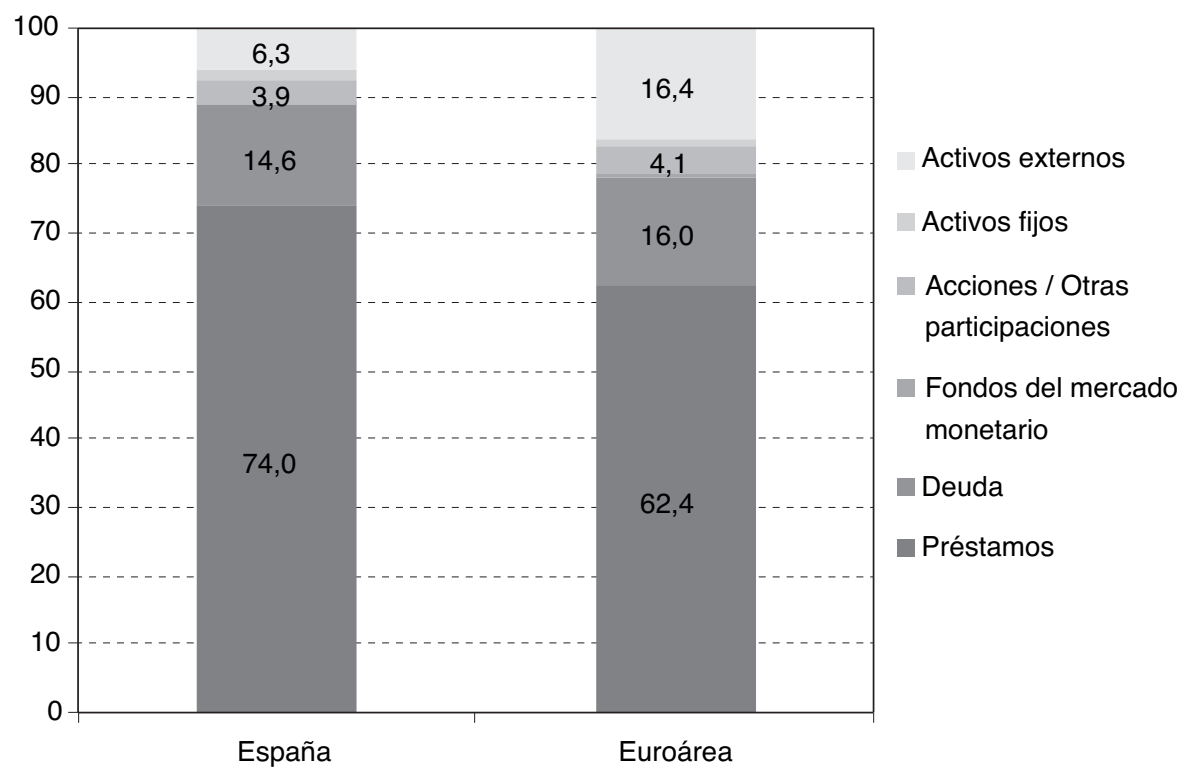

(b) 2016

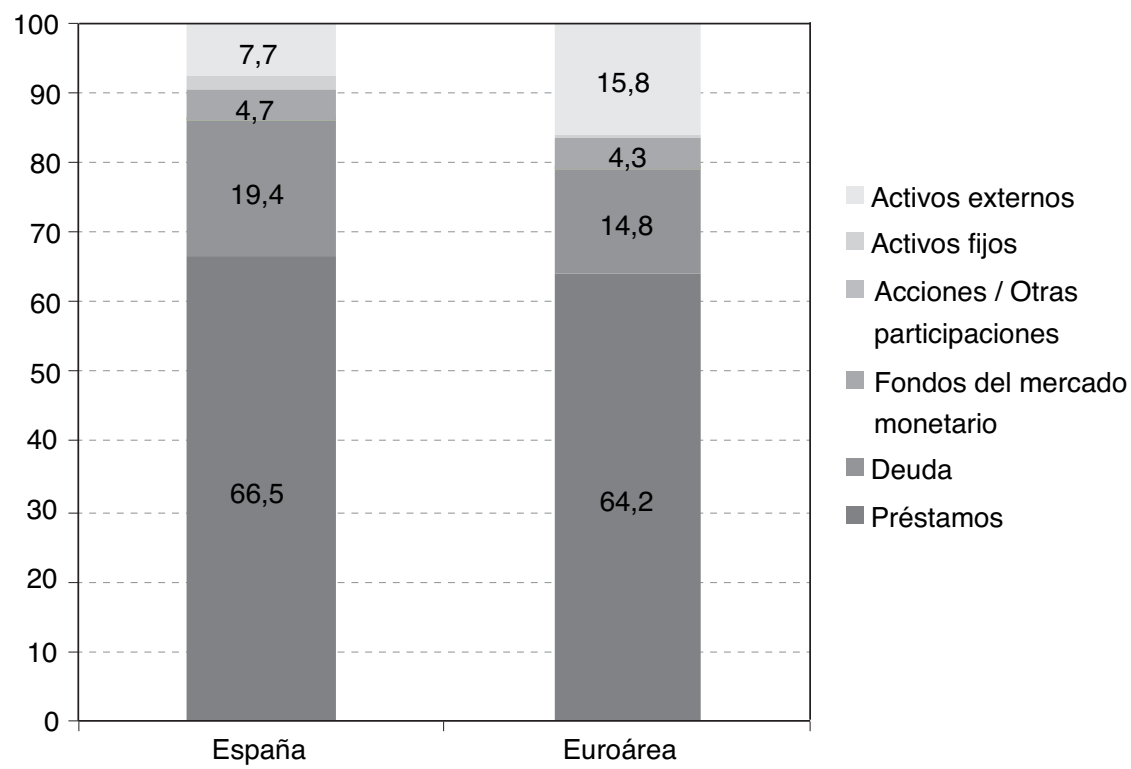

FUENTE: Banco Central Europeo. 


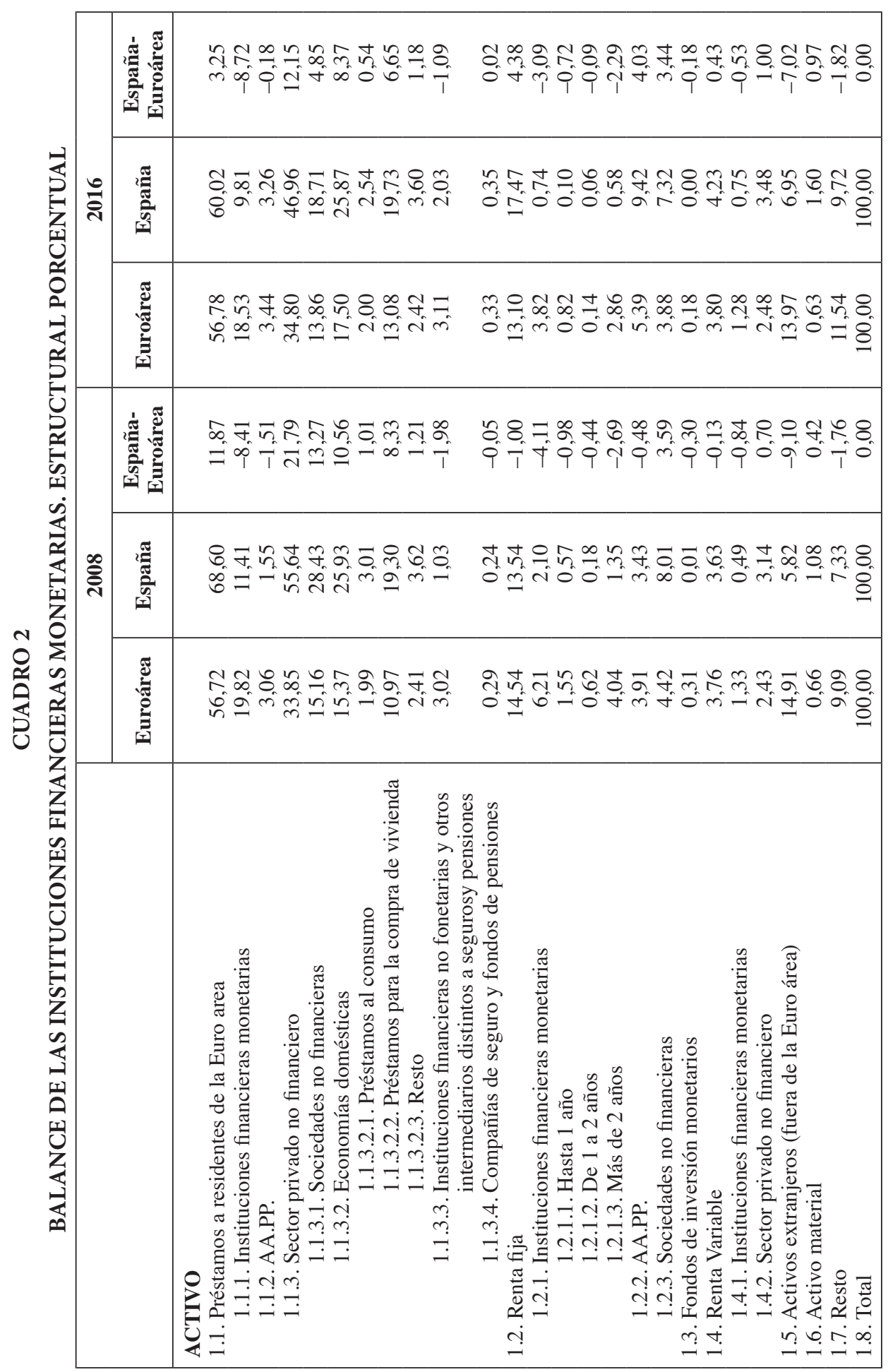




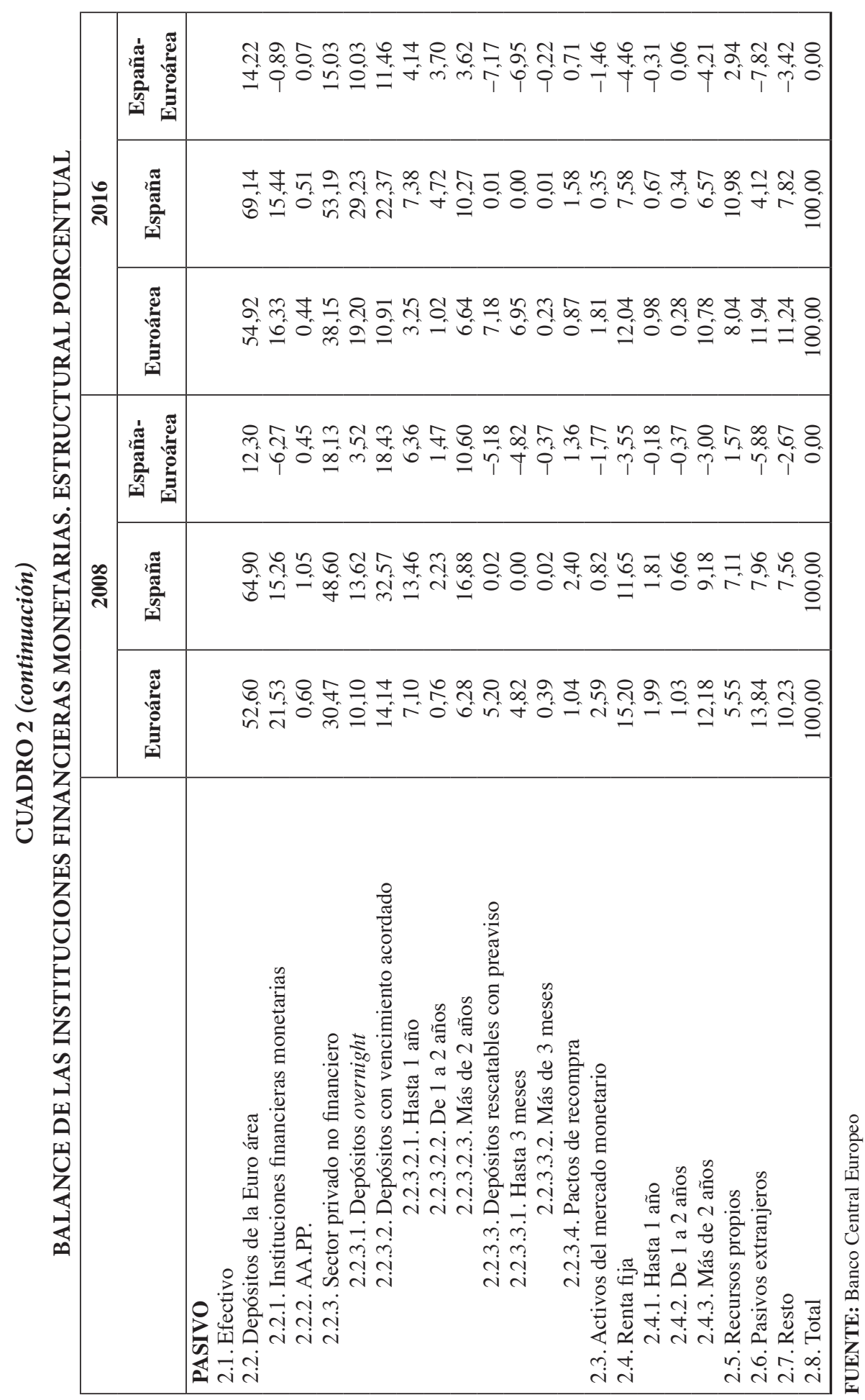




\section{GRÁFICO 6}

\section{DISTRIBUCIÓN PORCENTUAL DEL PASIVO DE LAS INSTITUCIONES FINANCIERAS MONETARIAS}

(a) 2008

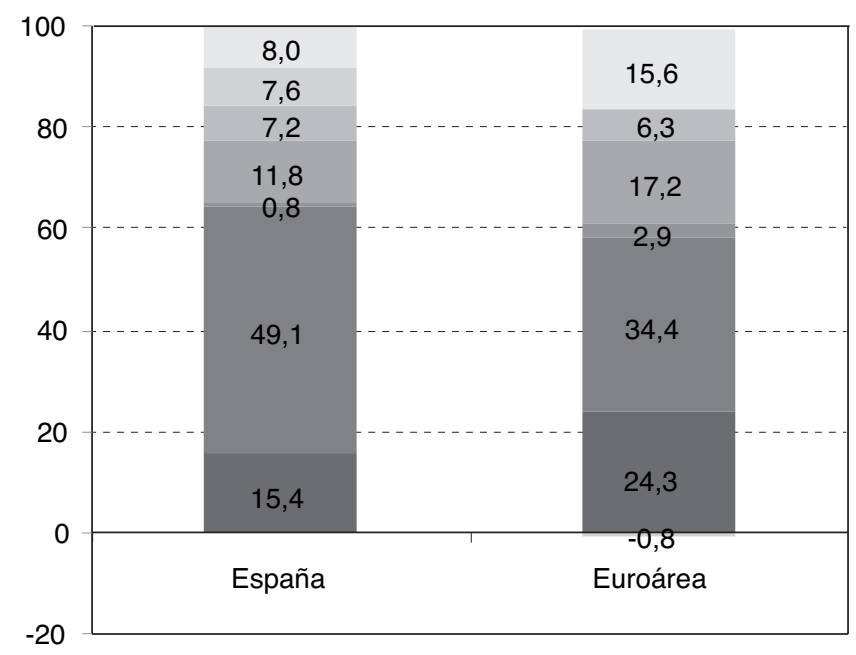

Pasivos externos

Otros pasivos

- Capital y reservas

Deuda

Fondos del mercado monetario

Depósitos del sector no financiero

- Depósitos de IFM

(b) 2016

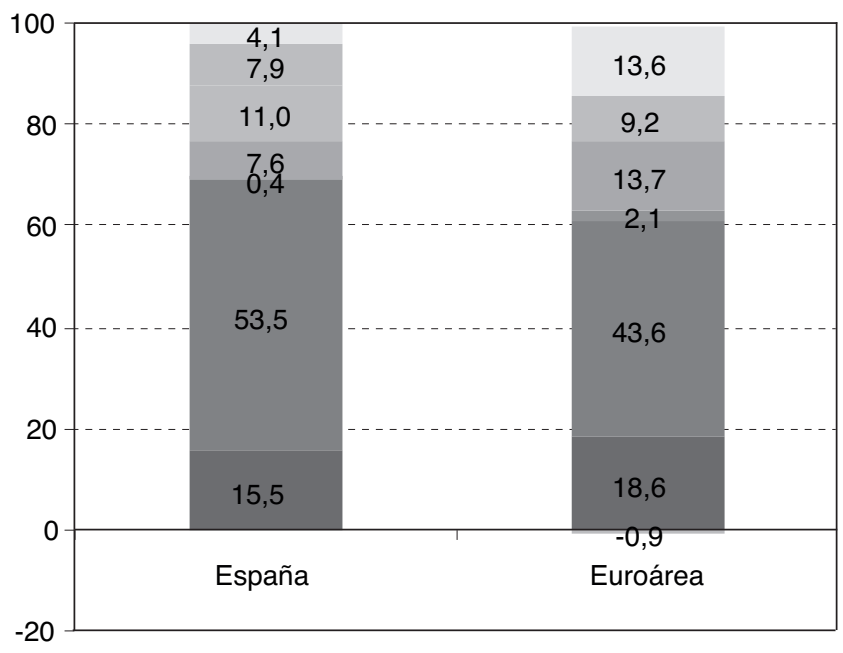

Pasivos externos

Otros pasivos

Capital y reservas

Deuda

- Fondos del mercado monetario

- Depósitos del sector no financiero

Depósitos de IFM

FUENTE: Banco Central Europeo. 


\section{Liquidez}

Uno de los desequilibrios que acumuló la banca española durante los años de expansión hasta 2008 fue un abultado gap de liquidez, dado que los depósitos privados no financieros eran insuficientes para financiar la burbuja crediticia. A nivel de los grupos consolidados, en 2008 la ratio créditos/depósitos era 1,14, y desde ese nivel máximo fue cayendo hasta situarse en 2016 en 0,9, lo que implica que el volumen de depósitos privados es más que suficiente para financiar el crédito al sector privado no financiero. Desde 2014, el gap de liquidez de la banca española es inferior al de la banca de la Euroárea.

Sin embargo, el problema de liquidez no está tanto en la banca española, sino en la banca en España, por lo que la visión cambia por completo cuando nos centramos en el negocio doméstico. En ese caso, aunque el valor no es comparable con el resto de países de la Euroárea porque el BCE da información de los grupos consolidados, en el mismo Gráfico 7 se ha dibujado el valor del gap de liquidez correspondiente al

\section{GRÁFICO 7}

GAP DE LIQUIDEZ: RATIO CRÉDITOS/DEPÓSITOS DEL SECTOR PRIVADO NO FINANCIERO

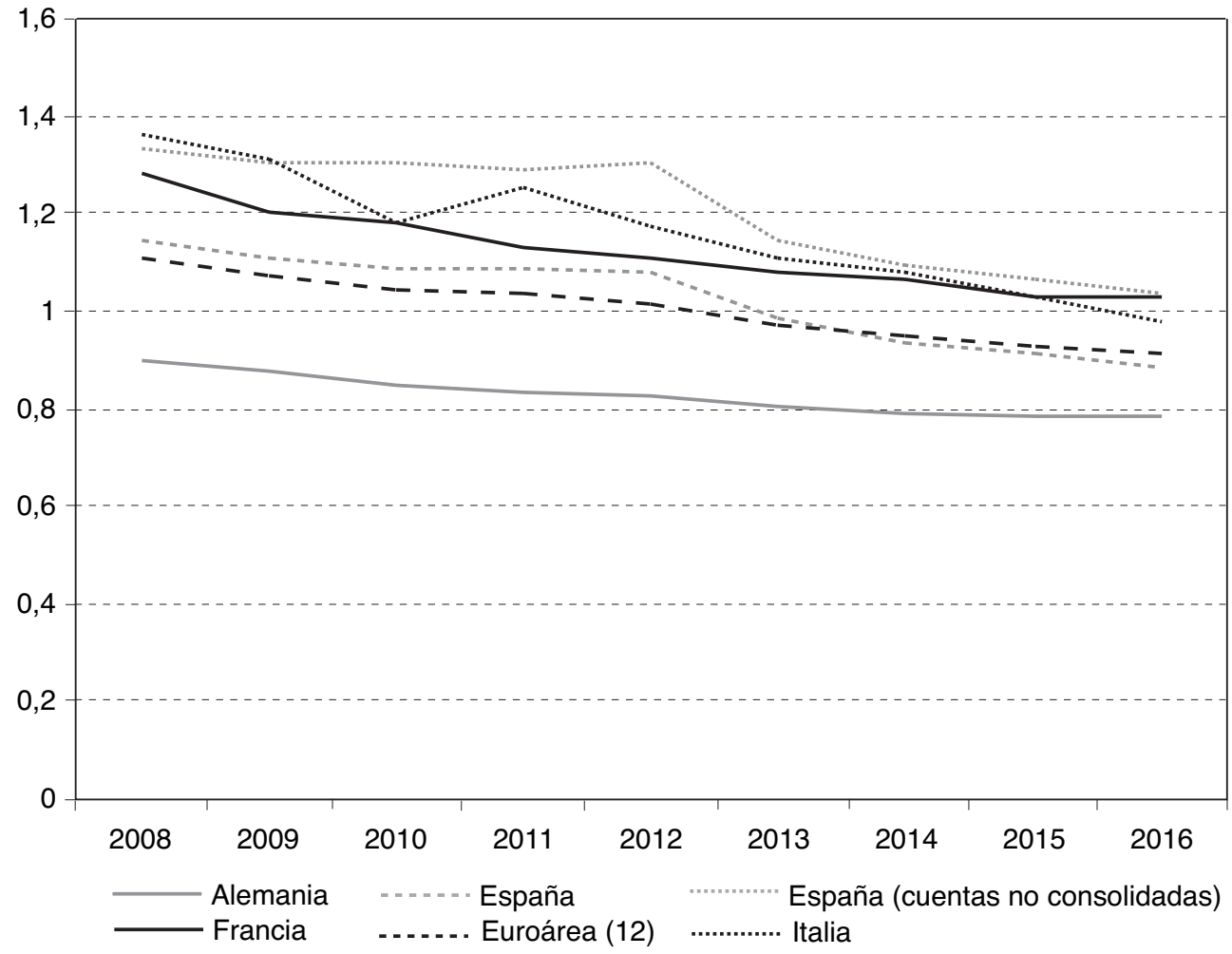

FUENTE: Banco Central Europeo. 
negocio de la banca española en España. En este caso, la ratio parte de 1,34 y termina en 2016 en 1,03, por lo que el gap de liquidez de 2008 de 440.000 millones de euros se ha reducido a solo 34.000 millones en 2016.

Otro indicador que refleja los problemas de liquidez que ha tenido la banca española en los años de crisis es la dependencia que ha tenido de la financiación del BCE y que ha alcanzado niveles muy abultados en el periodo de máxima tensión en la crisis de la Euroárea, en verano de 2012 (Gráfico 8). En concreto, en verano de ese año, solo dos meses después de que España pidiera asistencia financiera para inyectar capital en el sector bancario, la banca española debía al Eurosistema 402.000 millones de euros, lo que representaba el 34 por 100 del préstamo bruto total del BCE a la banca de la Euroárea, muy por encima del peso relativo de la banca española. Ese porcentaje se ha ido reduciendo y a finales de 2016 es del 25 por 100 que, aunque elevado, ha caído en valor absoluto a 145.000 millones de euros.

\section{GRÁFICO 8}

\section{DEPENDENCIA DE LA BANCA ESPAÑOLA DE LA FINANCIACIÓN DEL BCE} (En \%)

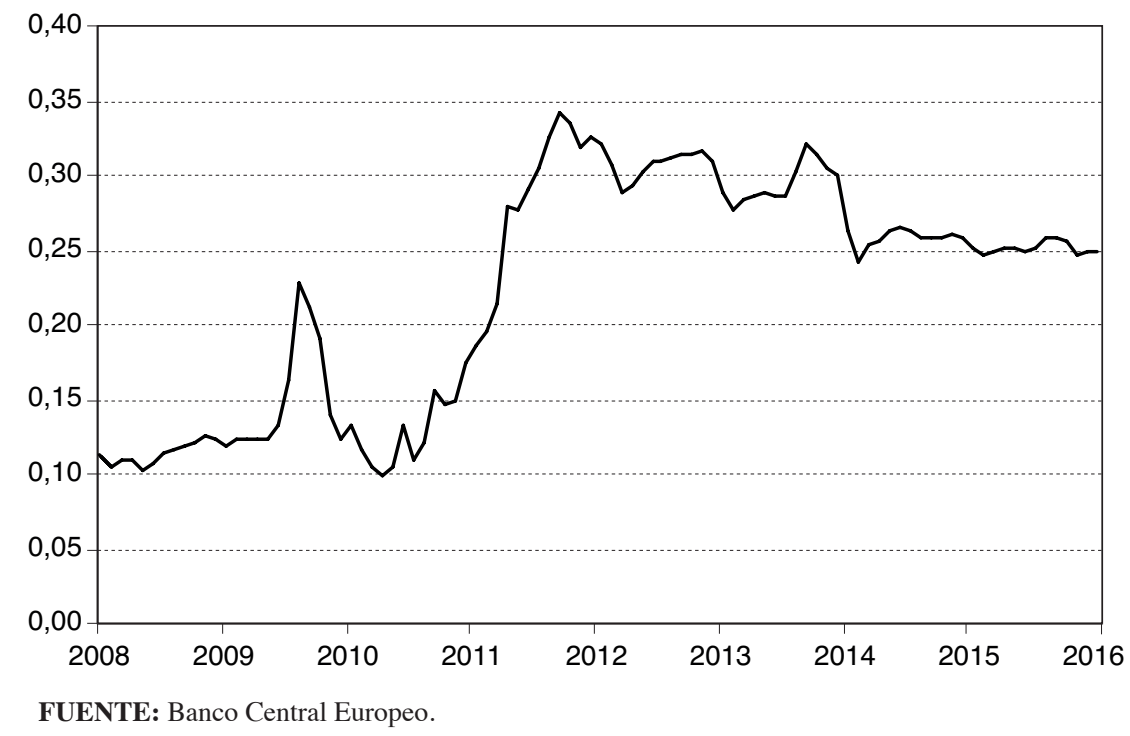

\section{Márgenes, eficiencia y rentabilidad}

El carácter retail, que posee especialmente la banca española y que conlleva mayores costes de estructura (oficinas, empleados, etc.), exige trabajar con un mayor margen financiero para asumir dichos costes. De hecho, tal y como se puede observar en el Gráfico 9, el margen financiero (como porcentaje del activo total) es mayor en el caso español que en resto de países de la Euroárea, exceptuando el caso de 


\section{GRÁFICO 9}

MARGEN DE FINANCIERO. PORCENTAJE DEL ACTIVO TOTAL

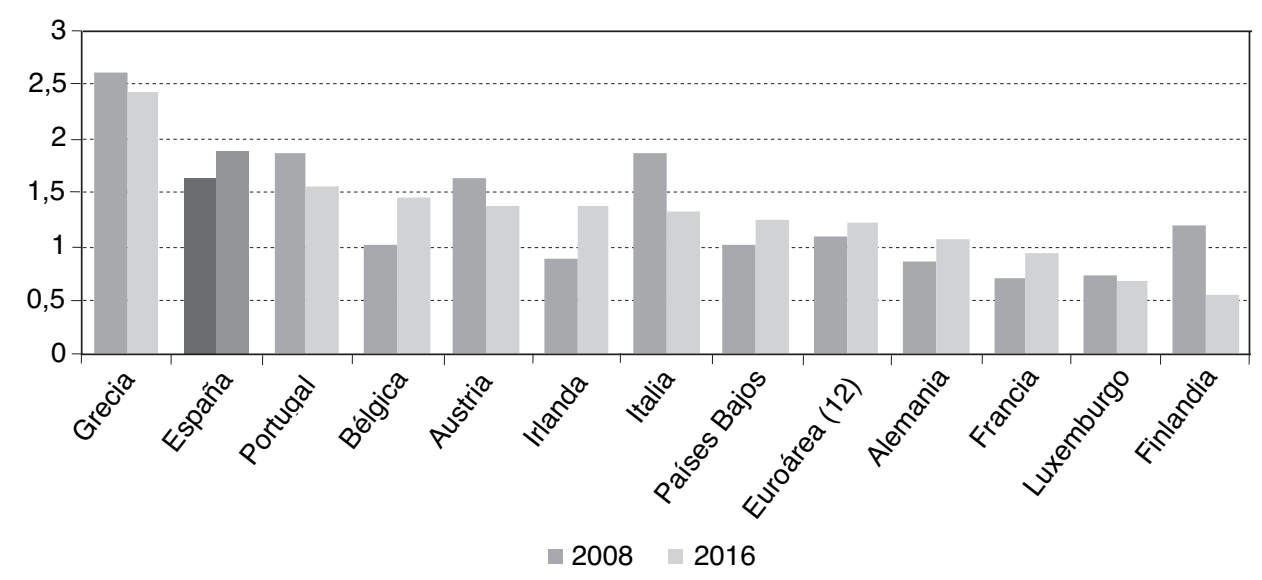

FUENTE: Banco Central Europeo.

Grecia. En 2016, el margen financiero de los bancos españoles, incluyendo tanto el negocio en España como el negocio de la banca española fuera de España, era del 1,88 por 100 , muy superior al promedio del sistema bancario de la Euroárea $(1,21$ por 100). Además, comparado con el margen existente en 2008, este se ha incrementado, pasando de 1,64 por 100 a 1,88 por 100 .

Sin embargo, pese al incremento sufrido por el margen de intereses, en el actual entorno de bajos tipos de interés, con diferenciales de tipos de interés pequeños, la sostenibilidad en el tiempo de este margen dependerá de la existencia de un nivel de actividad lo suficientemente grande como para permitir compensar vía cantidades. Por ello, las entidades además de variar el modelo de negocio (composición del balance) como estrategia defensiva ante las nuevas condiciones del entorno en el que se desenvuelve la actividad bancaria, han reaccionado buscando fuentes de ingresos distintas al margen neto de intereses. Por este motivo, es de especial interés analizar los cambios que se han producido en la estructura de ingresos de la banca española en el contexto internacional. En el Gráfico 10 puede observarse que los ingresos netos financieros en 2016 suponen en España 11,7 puntos porcentuales más que en la media de la Euroárea (63,9 por 100 frente a 52,2 por 100); mientras que en 2008 se daba la situación contraria ya que los ingresos financieros en la Euroárea suponían una mayor proporción de la estructura de ingresos que en España (65 por 100 frente a 61,24 por 100). Entre los ingresos no financieros en España, cabe destacar los ingresos por comisiones, que suponen un 22,68 por 100 del total de ingresos netos, seguidos en importancia por los ingresos por renta variable (dividendos). En el caso español, parece clara la búsqueda de fuentes de ingresos alternativas a la actividad tradicional de intermediación. 


\section{GRÁFICO 10}

ESTRUCTURA PORCENTUAL DE INGRESOS LOS INGRESOS NETOS DE LAS ENTIDADES DE CRÉDITO

(a) 2008

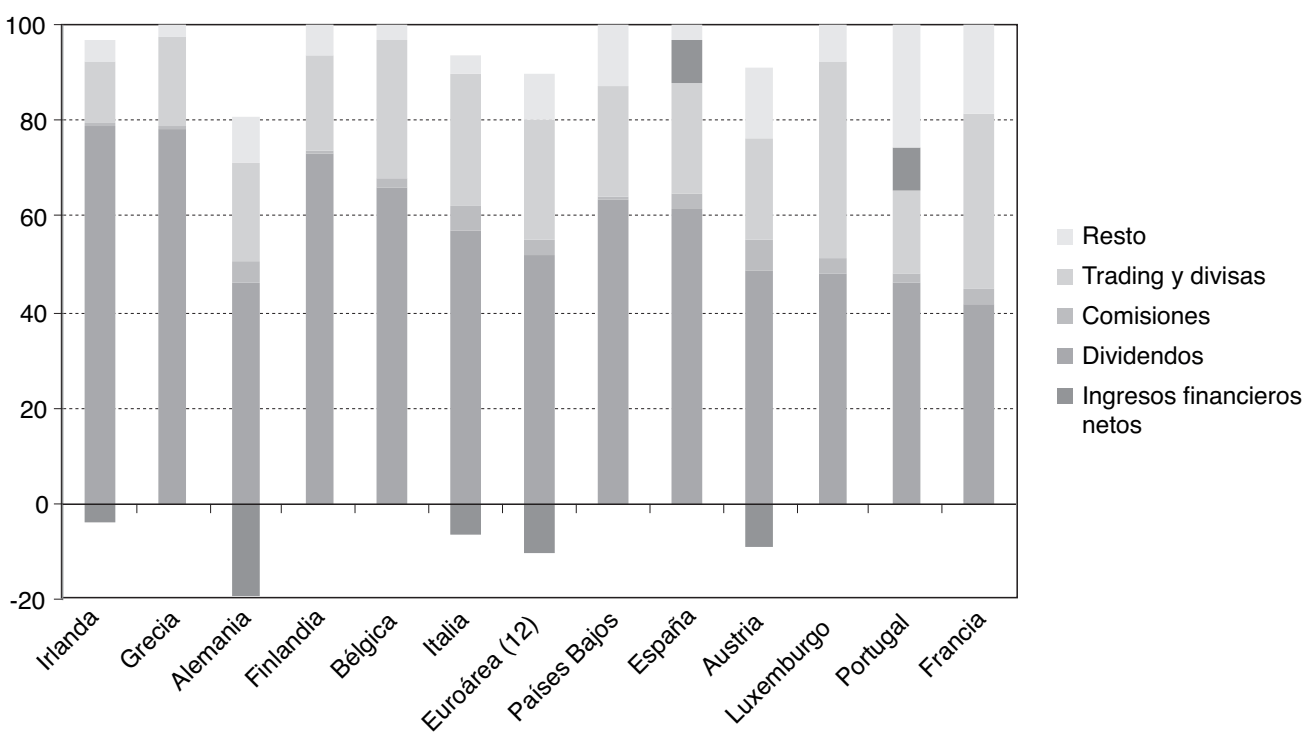

(b) 2016

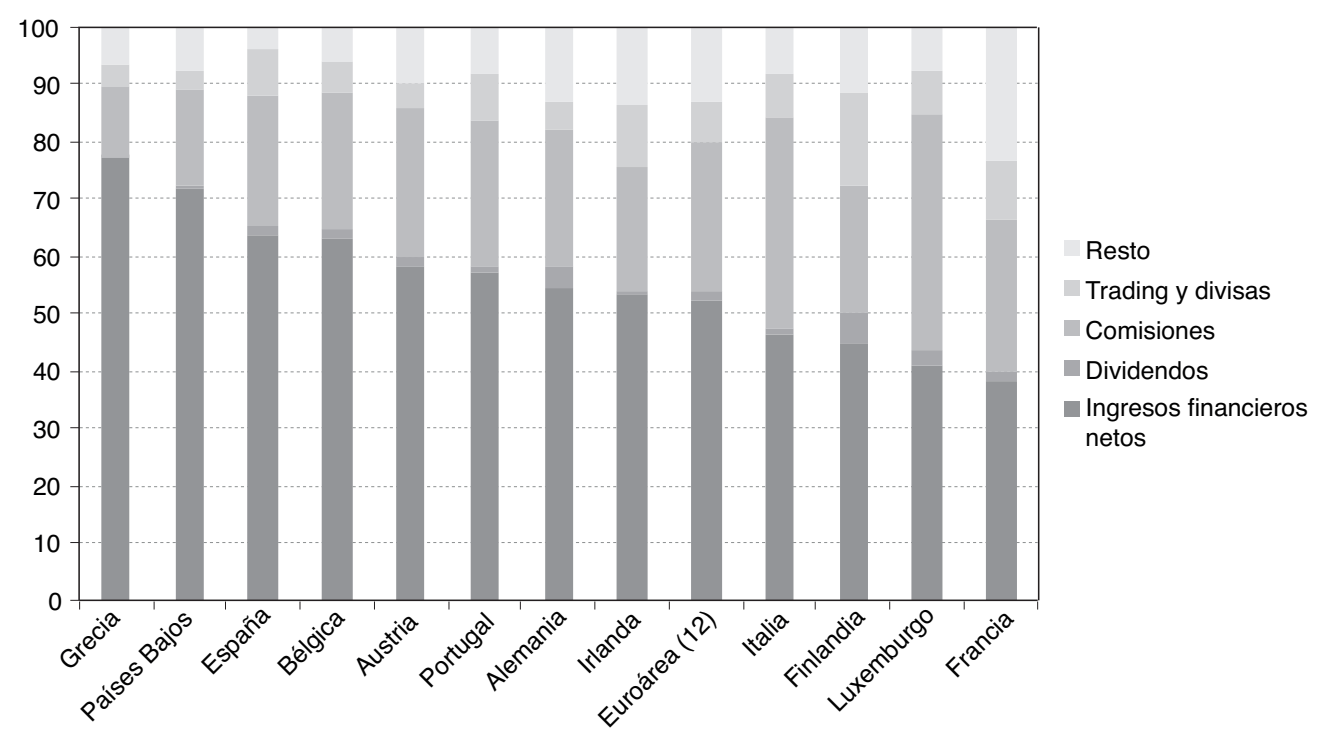

FUENTE: Banco Central Europeo. 
Teniendo en cuenta esta estructura y peso en el activo de los ingresos, podemos observar en el Gráfico 11 que el margen ordinario como porcentaje del activo en España en 2016 está muy por encima del de la media de la Euroárea (2,80 por 100 frente a 2,11 por 100), siendo igualado por Italia y únicamente superado por Grecia. Así también, se puede observar que el margen ordinario se ha incrementado 0,69 puntos porcentuales desde el año 2008.

\section{GRÁFICO 11}

MARGEN DE ORDINARIO. PORCENTAJE DEL ACTIVO TOTAL

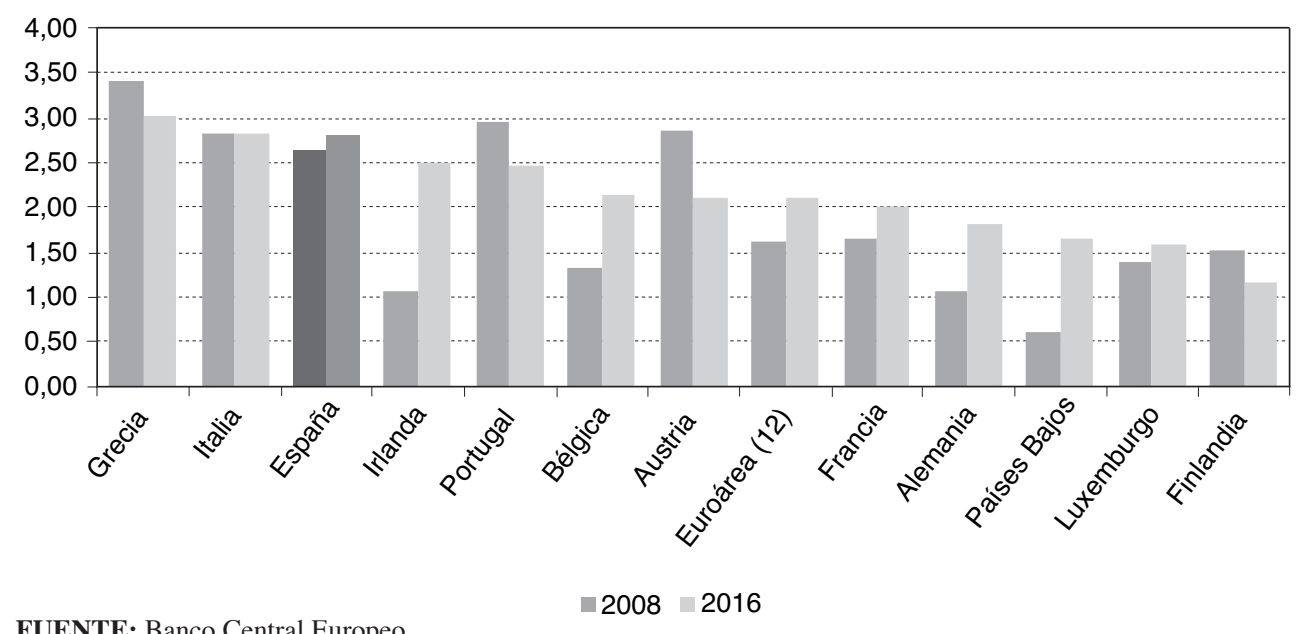

FUENTE: Banco Central Europeo.

Pese al esfuerzo en reestructuración tras la crisis financiera, los costes operativos medios se han incrementado de 2008 a 2016, situándose en un 1,46 por 100. Este aumento se debe a la importante caída del negocio bancario, que al caer más que los gastos de explotación, hace que los costes unitarios hayan aumentado. Tal y como se puede observar en el Gráfico 12, en términos de costes medios, España se encuentra por encima de la media de la Euroárea (1,36 por 100) y es únicamente superada por Grecia, Italia y Portugal.

Sin embargo, pese a que España se encuentra entre los primeros puestos del ranking en términos de costes operativos, destaca por su alto nivel de eficiencia operativa, entendida como la relación entre el conjunto de ingresos netos obtenidos (margen bruto u ordinario) y los costes de explotación asumidos. Tal y como se puede observar en el Gráfico 13, España es mucho más eficiente que el resto de países de la Euroárea, situando su ratio de eficiencia en el 52,2 por 100 frente al 64,2 por 100 de la media de los países miembros de la UEM. En los últimos años, la eficiencia de la banca española se ha incrementado gracias a la recuperación del margen en 2014. Sin embargo, 


\section{GRÁFICO 12}

\section{COSTES OPERATIVOS. PORCENTAJE DEL ACTIVO TOTAL}

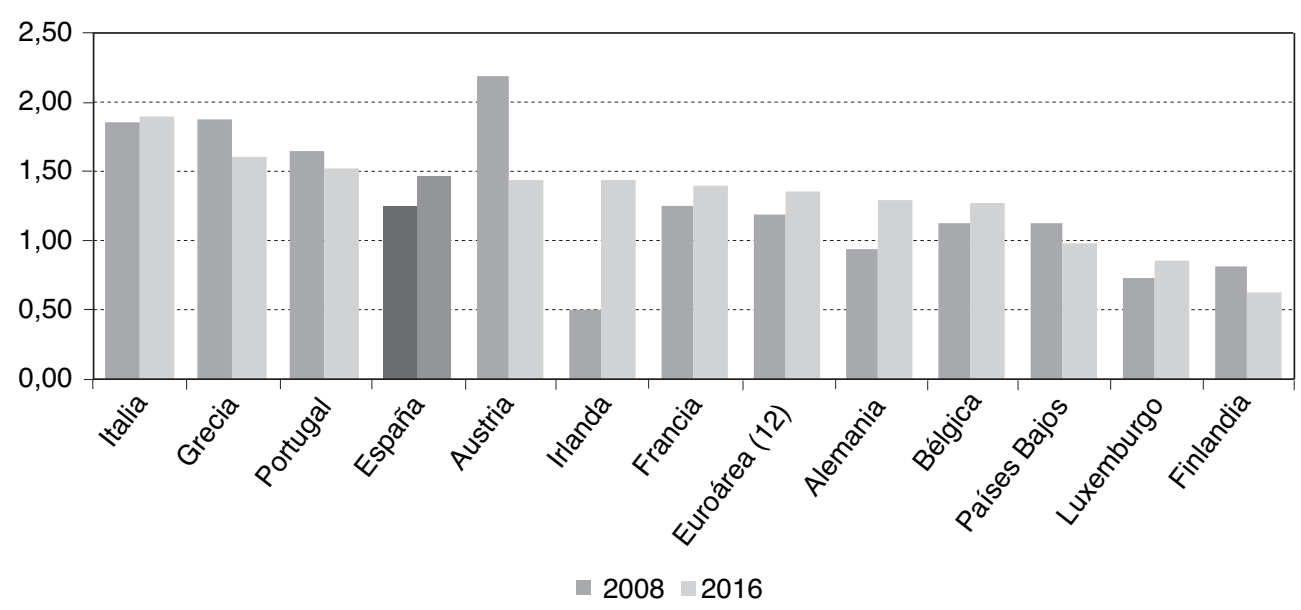

FUENTE: Banco Central Europeo.

\section{GRÁFICO 13}

\section{RATIO DE EFICIENCIA OPERATIVA}

(En \%)

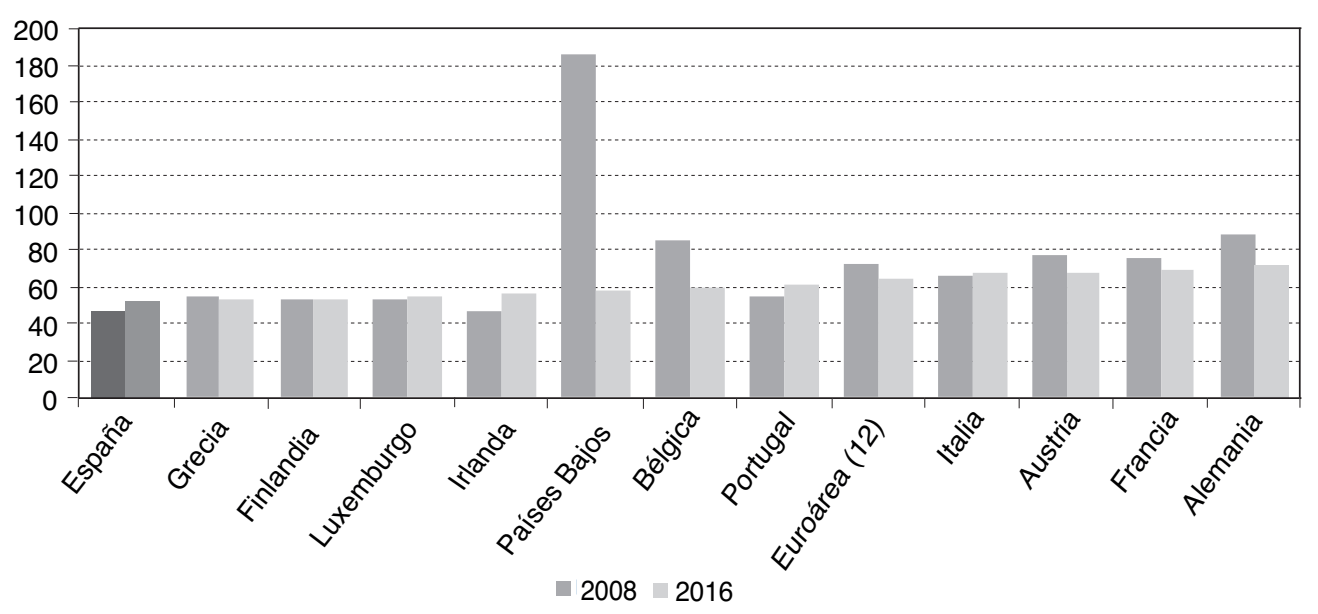

FUENTE: Banco Central Europeo.

comparando el dato actual con el existente en 2008, observamos que España ha sufrido una pérdida de eficiencia, coincidente con el incremento en los costes operativos.

Si bien España cuenta con un nivel alto de costes operativos, el margen operativo o de explotación (Gráfico 14) se ha incrementado ligeramente de 2008 a 2016, 


\section{GRÁFICO 14 \\ MARGEN DE EXPLOTACIÓN. PORCENTAJE DEL ACTIVO TOTAL}

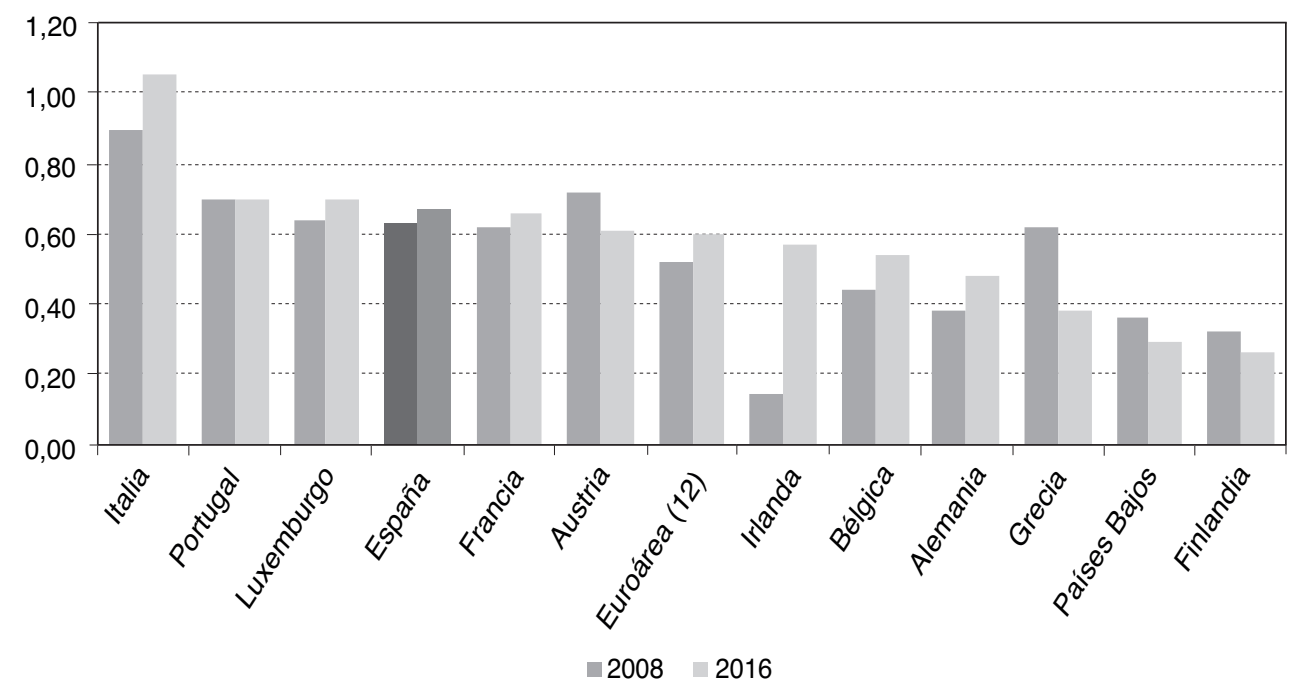

FUENTE: Banco Central Europeo.

situándose en el 0,67 por 100 , por encima del 0,60 por 100 de la media de la Euroárea.

En términos de rentabilidad, el sistema bancario español también destaca en el contexto europeo. En el caso del resultado antes de intereses e impuestos en relación al activo (ROA), este se ha reducido del 0,68 por 100 en 2008 al 0,54 por 100 en 2016, en el caso del negocio consolidado, tal y como se puede observar en el Gráfico 15. En el caso de los recursos propios, el Gráfico 16 muestra que su rentabilidad (ROE) pasa del 12,4 por 100 en 2008 al 6,9 por 100 en 2016. Sin embargo, pese a esta reducción de la rentabilidad, España se encuentra en la actualidad, tanto en términos de ROA como de ROE, por encima de la media de la Euroárea (que cuenta en 2016 con un ROA del 0,33 por 100 y de un ROE del 5,13 por 100) y de los principales países de la misma, como Francia o Alemania. No obstante, tanto la rentabilidad de la banca de la Euroárea como de la banca española, se encuentra por debajo del coste de captar capital (entre el 8 por 100 y el 10 por 100), resultando insuficiente.

Un tema de reflexión y preocupación en la actualidad, es el efecto sobre la rentabilidad bancaria de la política monetaria expansiva que está llevando a cabo el Banco Central Europeo, sobre todo cuando los tipos de interés de referencia han alcanzado niveles tan reducidos como los actuales. Diversos trabajos empíricos (Cruz-García et al., 2017; entre otros) han demostrado que el extenso periodo de bajos tipos de interés está erosionando el margen de intermediación y, por tanto, ceteris paribus, la rentabilidad. 


\section{GRÁFICO 15 \\ RENTABILIDAD SOBRE ACTIVO (ROA) \\ (En \%)}

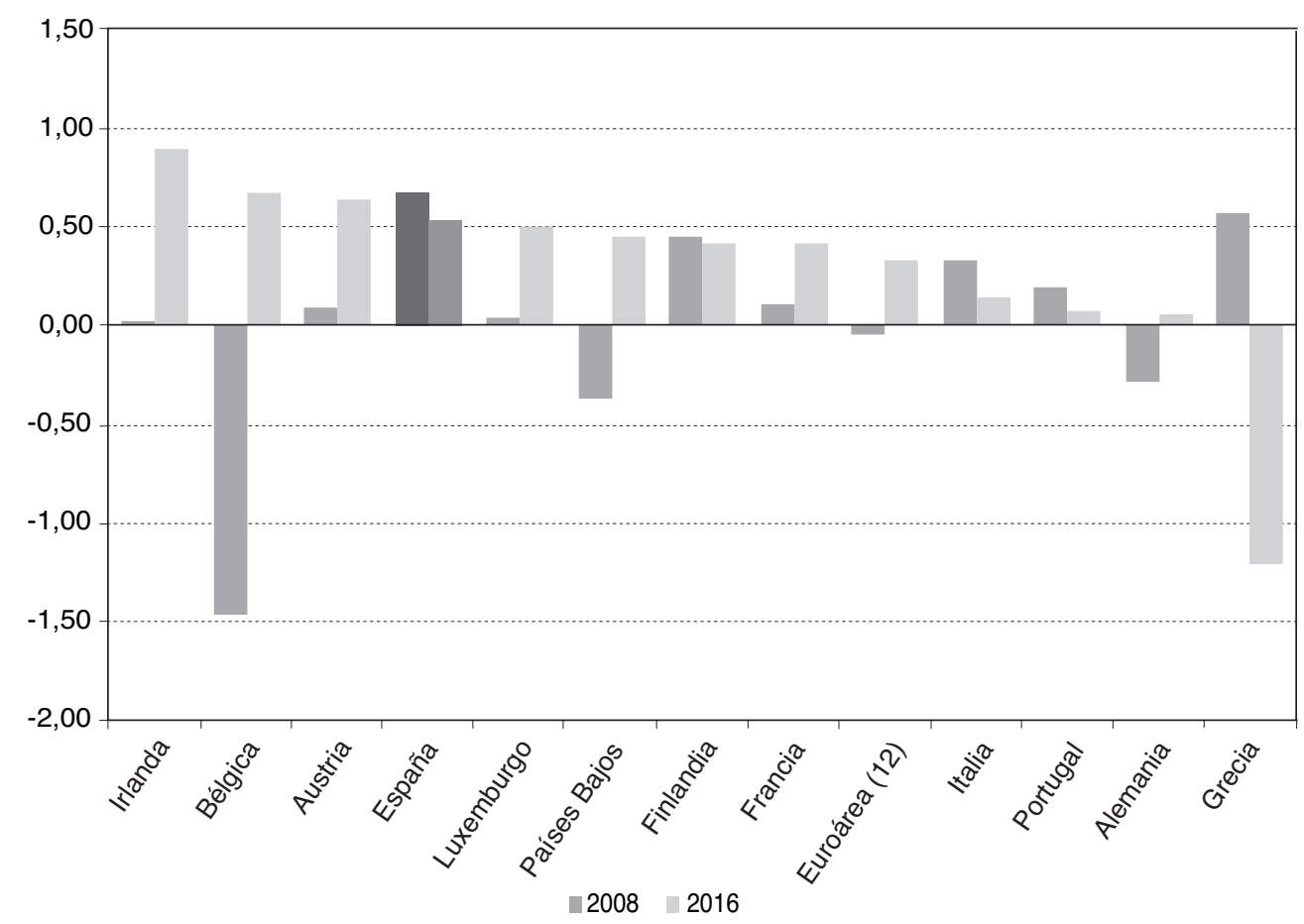

FUENTE: Banco Central Europeo.

Teniendo en cuenta la reducida tasa de crecimiento del PIB y el actual escenario de tasas de inflación muy reducidas y alejadas del objetivo del 2 por 100 del BCE, se pronostica el mantenimiento del tono expansivo de la política monetaria (con tipos de interés muy reducidos) durante mucho tiempo. En este contexto, la banca europea $\mathrm{y}$, especialmente, la banca española, deberá reducir costes para continuar ganando eficiencia, a la vez que aumentar la importancia de los ingresos distintos al cobro de intereses. 


\section{GRÁFICO 16 \\ RENTABILIDAD SOBRE RECURSOS PROPIOS (ROE) \\ (En \%)}

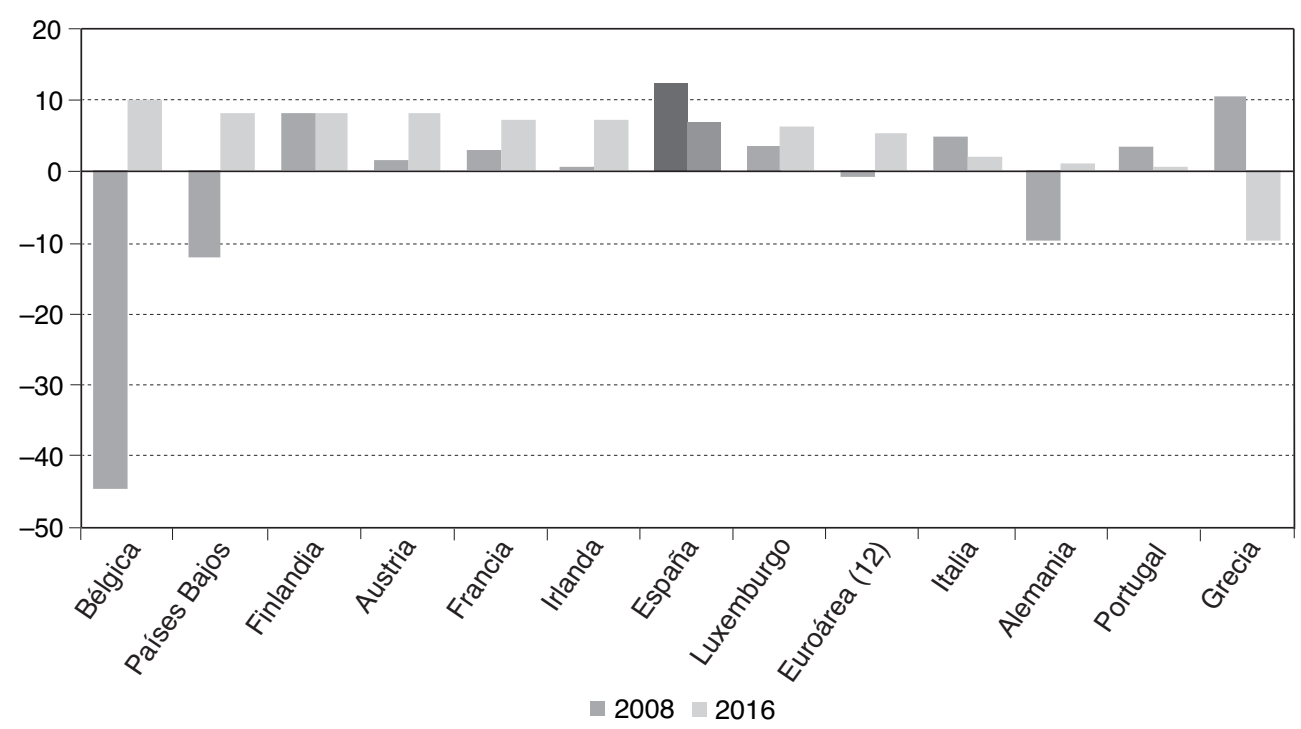

FUENTE: Banco Central Europeo.

\section{Calidad del activo}

Una de las variables que más ha sufrido durante la crisis es la morosidad bancaria como consecuencia de la pérdida de valor de los activos. El BCE ofrece información de la tasa de dudosidad para el total de la actividad bancaria, y no para el caso particular del crédito. Como muestra el Gráfico 17, en España la tasa de dudosidad se ha duplicado en 2008 a 2015, pasando del 2,7 por 100 al 4,9 por 100. En 2015 las tasas más elevadas corresponden a la banca de Grecia (39 por 100), Chipre (35 por $100)$, Italia (15,5 por 100) y Portugal (14,7 por 100), mientras que en países como Alemania, Finlandia y Suecia no llegan al 2 por 100. En el caso del préstamo, la información más reciente (diciembre 2016) para España (negocio doméstico) la sitúa en el 9,1 por 100 y llegó a alcanzar un máximo del 13,5 por 100 a mediados de 2014. Desde entonces ha caído de forma casi ininterrumpida.

Tal y como se puede observar en el Gráfico 18, del volumen de activos dudosos, la cobertura con provisiones se sitúa en la actualidad en España (59,5 por 100) por encima de la media de la Euroárea (50,9 por 100), lo que es un buen y claro indicador del esfuerzo de saneamiento realizado. Esta tasa de cobertura es similar a la de Francia (60 por 100$)$ y superior a la de Alemania $(43,2$ por 100$)$ e Italia $(49,7$ por 100$)$. En este último caso, la preocupación que existe en estos momentos sobre la banca italiana reside en su alta morosidad, por un lado, y la baja tasa de cobertura, por otro. 


\section{GRÁFICO 17}

TASA DE DUDOSIDAD. PORCENTAJE DE LA EXPOSICIÓN TOTAL

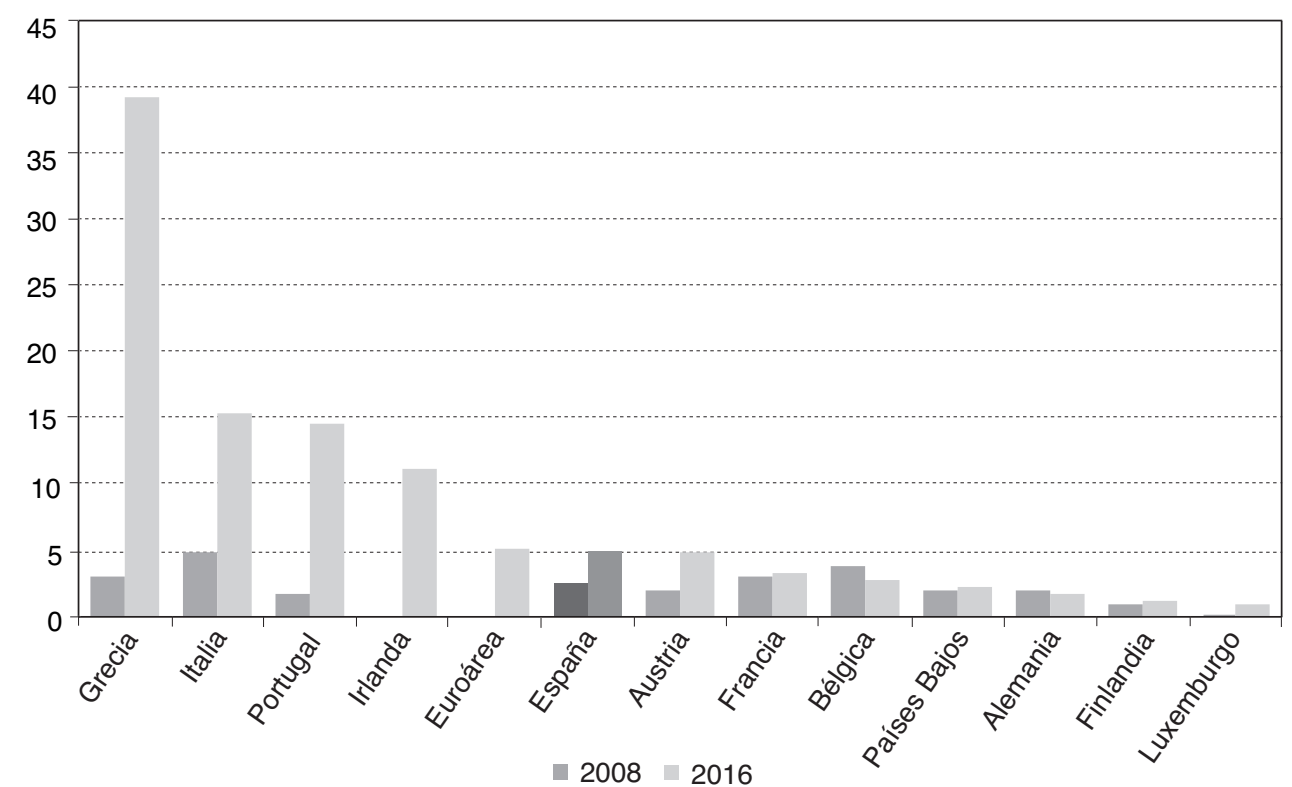

FUENTE: Banco Central Europeo.

\section{GRÁFICO 18}

TASA DE COBERTURA CON PROVISIONES DE LA MOROSIDAD

(En \%)

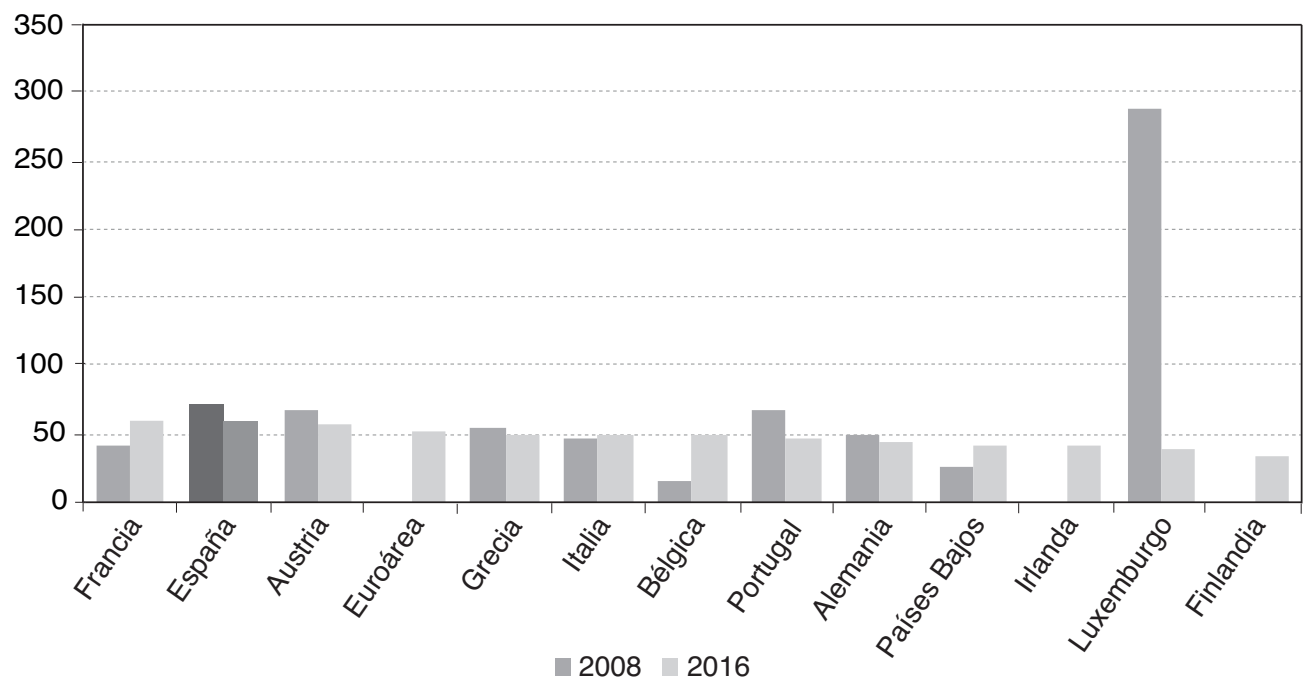

FUENTE: Banco Central Europeo. 
Como se ha señalado en varias ocasiones, la banca española ha hecho un enorme esfuerzo de saneamiento desde que estallara la crisis para asumir las pérdidas por el deterioro de los activos bancarios, sobre todo los inmobiliarios. De forma acumulada en el periodo analizado 2008-2015, como muestra el Gráfico 19, España es el segundo país de la Euroárea que más recursos ha destinado a reconocer el deterioro de los activos bancarios, con un saneamiento equivalente al 29 por 100 del PIB, solo por detrás de Grecia (83 por 100) y casi triplicando el valor del promedio europeo (11 por 100). La intensidad del saneamiento realizado demuestra que son las propias entidades bancarias las que han asumido la mayor parte del coste de la crisis, detrayendo recursos de su margen de explotación para hacer frente al deterioro del activo.

\section{GRÁFICO 19}

SANEAMIENTO ACUMULADO DE 2008 A 2015 (PÉRDIDAS POR DETERIORO DE ACTIVO) (PORCENTAJE DEL PIB)

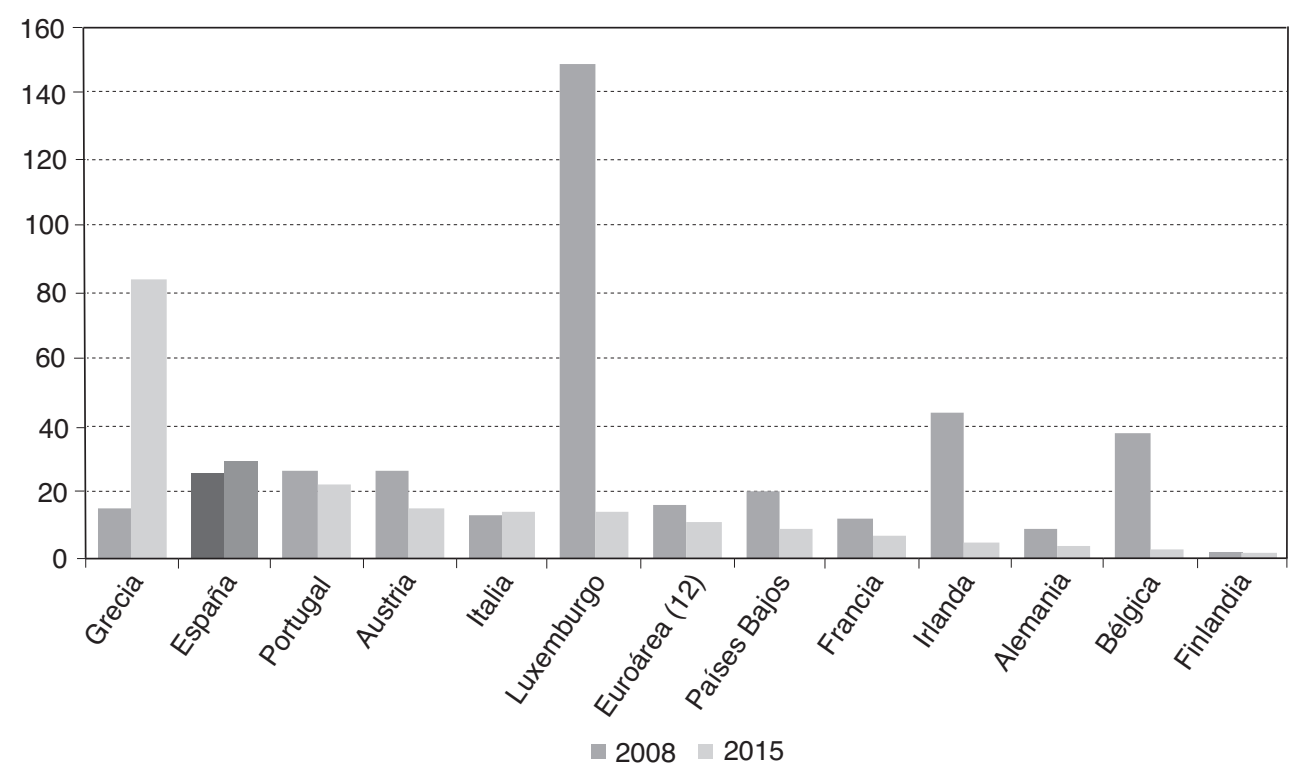

FUENTE: Banco Central Europeo.

\section{La solvencia de la banca española en el contexto europeo}

Una de las principales lecciones de la reciente crisis financiera es la insuficiencia de capital de calidad para absorber las multimillonarias pérdidas que ha ocasionado la crisis y que ha obligado a revisar por completo los «viejos» acuerdos de Basilea II dando paso a Basilea III, que exige más capital y de mayor calidad. 
Las mayores exigencias regulatorias han obligado a los bancos a realizar un importante esfuerzo de capitalización para adaptarse progresivamente a los nuevos acuerdos. Es algo que se aprecia claramente en el Gráfico 20, donde se representa la variación en puntos porcentuales del coeficiente de solvencia desde 2008 a 2015. Para la media (no ponderada) de países de la Euroárea, ha aumentado 6,5 pp., mientras que en España ha aumentado 3,7 pp. hasta situarse en el 15 por 100, frente al 18,5 por 100 de la media europea.

El ranking en 2015 del coeficiente de solvencia sitúa a España en una situación muy rezagada, siendo el segundo país de la Euroárea con menor ratio, solo por delante de Portugal. Los principales sectores bancarios europeos presentan coeficiente de solvencia del 17,9 por 100 en el caso de Alemania, 16,9 por 100 en Francia y 15,2 por 100 en Italia.

La posición rezagada del sector bancario español se repite en términos del coeficiente de solvencia de mayor calidad (CET1) y de Tier 1. En el primer caso, que es el capital de mayor calidad, España es el tercer país de la Euroárea con menor ratio, por delante de Italia y Portugal.

\section{GRÁFICO 20}

COEFICIENTE DE SOLVENCIA. PORCENTAJE DE LOS ACTIVOS PONDERADOS POR RIESGO

\section{(a) Total}

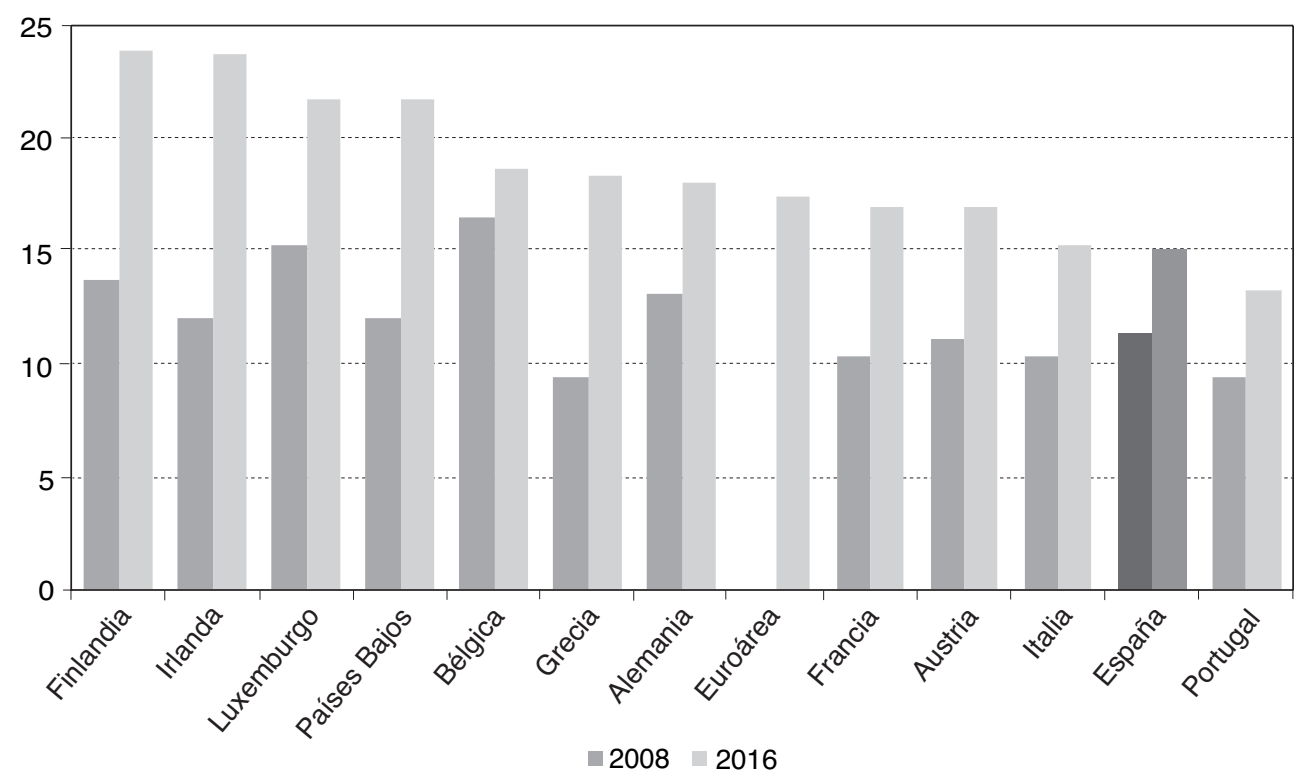

FUENTE: Banco Central Europeo. 


\section{GRÁFICO 20 (continuación) \\ COEFICIENTE DE SOLVENCIA. PORCENTAJE DE LOS ACTIVOS PONDERADOS POR RIESGO}

\section{(b) Tier 1 y CET1. Año 2016}

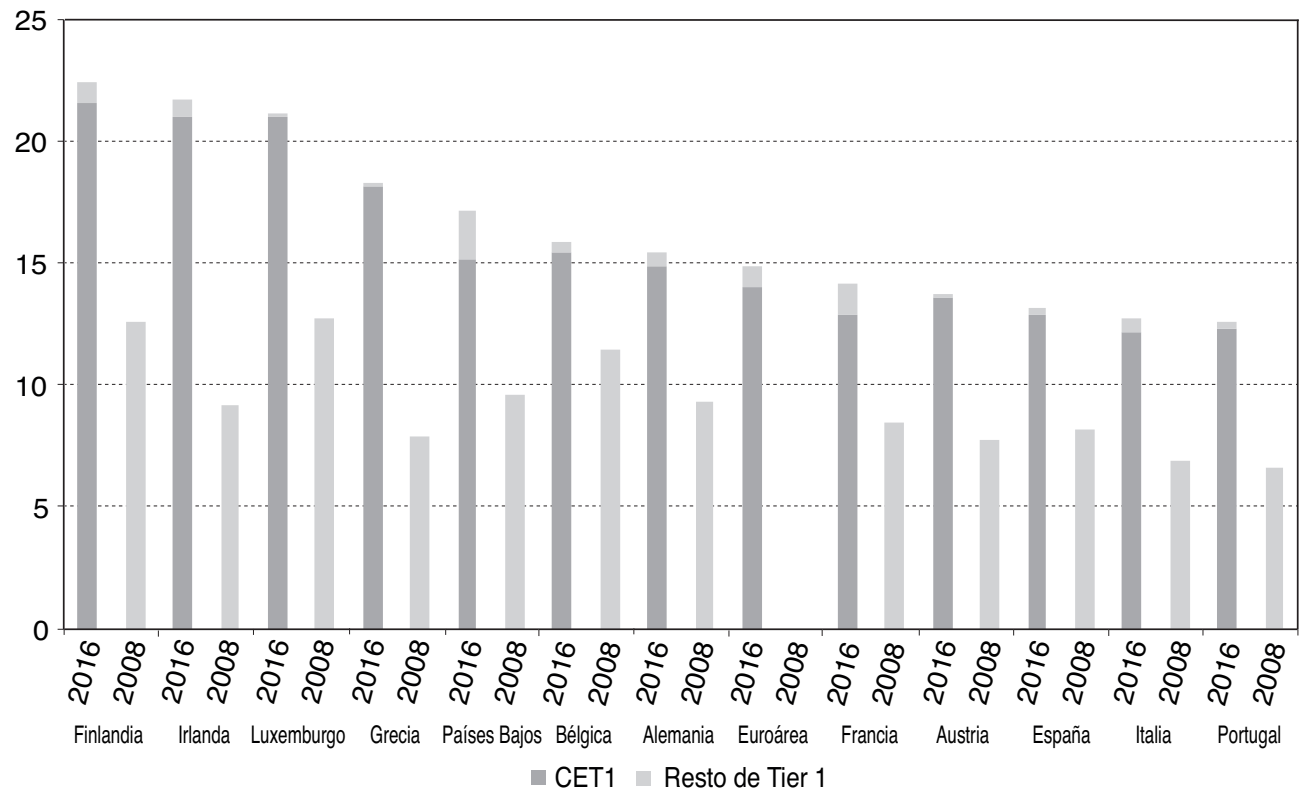

FUENTE: Banco Central Europeo.

\section{Conclusiones}

Tras sufrir un rescate y asistencia de los fondos europeos en 2012, el sector bancario español ha implementado una larga lista de reformas que hace que la situación actual del sector no tenga nada que ver con la que existía en el inicio de la crisis en 2008. Atrás ha quedado el exceso de capacidad instalada, la insuficiencia de provisiones para hacer frente a un elevado nivel de morosidad, la escasa capitalización o el excesivo gap de liquidez, entre otros. El sector superó con éxito las pruebas de resistencia que hizo el BCE en 2014 como condición previa a asumir el mecanismo único de supervisión (MUS), siendo un indicador del éxito de la reestructuración llevada a cabo.

A pesar de que lo peor de la crisis bancaria ya es historia del pasado, el sector bancario español comparte con el europeo un reto muy importante y es conseguir que la rentabilidad supere el coste de captar capital, que es la condición a largo de plazo de viabilidad del sector.

Este importante reto del sector bancario no es fácil de superar a corto y medio plazo por un conjunto de condicionantes que configuran un entorno complicado para 
el negocio bancario: a) unos tipos de interés de referencia en los mercados históricamente bajos y nunca antes vistos, lo que lastra al margen de intermediación y por tanto a la rentabilidad; b) mayores exigencias regulatorias, tanto en términos de liquidez como de capital, a lo que se acompaña la incertidumbre sobre el fin de esa presión en la regulación; c) la unión bancaria configura un escenario de mayor competencia a nivel europeo; y d) la digitalización de la actividad bancaria, a la que se une la presencia de nuevos actores que compiten con la banca como las fintech. Es lógico que en este escenario la banca no despierte el atractivo de los inversores, como demuestra que coticen muy por debajo de su valor en libros, descontando el mercado niveles de rentabilidad insuficientes.

¿Qué puede hacer la banca para aumentar su rentabilidad? Las respuestas que hasta ahora ha dado apunta en las siguientes direcciones: a) cambios en el modelo de negocio, alterando la composición del balance, tanto en el activo (menor peso del crédito, mayor importancia de la renta fija) como en el pasivo (creciente peso de los recursos propios, pérdida de importancia de la financiación en los mercados en beneficio de los depósitos); b) alteración de la estructura de ingresos, aumentando los ingresos distinto al cobro de intereses (especialmente las comisiones) en detrimento del margen de intermediación; c) ahorrando costes, lo que implica seguir ajustando la capacidad instalada; d) digitalización de la actividad bancaria para responder a la demanda de este tipo de servicios, así como estrategia para ganar eficiencia. El sector bancario español se ha movido en esta dirección en los últimos años, con cambios en la estructura de su balance (en la dirección comentada) y en la composición de sus ingresos, y con ajustes de capacidad para ahorrar costes.

El problema es que a pesar de las respuestas ya adoptadas, no son suficientes en tanto las condiciones del entorno se mantengan en el tiempo. Mientras la política monetaria del BCE siga siendo tan expansiva, los tipos de interés seguirán lastrando la cuenta de resultados. Y si bien las últimas decisiones del BCE suponen un tímido relajamiento en su Quantitative Easing (desde abril a diciembre de 2017 ha caído de 80.000 a 60.000 millones de euros mensuales la cantidad de activos a comprar en los mercados), el tono de la política sigue siendo muy expansivo, por lo que de momento los tipos tan bajos probablemente seguirán más tiempo.

En este contexto, la banca española tendrá que seguir ajustando aún más su capacidad instalada para reducir costes. Además, España sigue teniendo una de las redes de oficinas más densas de Europa, y ocupa el último lugar del ranking en término de número de empleados por oficina. Por tanto, hay margen de maniobra más que suficiente para seguir cerrando oficinas. Más aún conforme sigue avanzando el uso de la banca online y otras aplicaciones a través de internet que reducen el peso de las operaciones en las oficinas.

Las fusiones siempre han sido una de las vías más utilizadas para reducir costes, sobre todo aprovechando economías de escala. Lo ha sido en el pasado reciente (fusiones entre cajas de ahorros) y es previsible que lo siga siendo en el nuevo escenario de la unión bancaria. Algunas de las actuales entidades bancarias tienen un tamaño atractivo para las fusiones, aunque eso es compatible con que haya entidades de 
tamaño reducido con un nicho de mercado más local (como es el caso de las cooperativas de crédito). En cualquier caso, es necesario que se busquen sinergias entre estas entidades pequeñas, para mejorar su acceso a los mercados y también para ahorrar costes (compartiendo algunos servicios).

En el contexto europeo, ahora mismo la banca española sale bien parada en términos de rentabilidad y eficiencia, dos de los principales indicadores de gestión. En cambio, se sitúa en posiciones muy rezagas en términos de solvencia, si bien estos indicadores deben ser interpretados con prudencia dado el diferente tratamiento de los activos ponderados por riesgo. De hecho, España avanza bastantes puestos en el ranking en términos de capitalización. No obstante, dado que todavía no se ha completado el calendario regulatorio (hasta el fully loaded) y que cada vez aparecen nuevas exigencias (como los Total Loss Absorption Capacity (TLAC) o los Minimum Requirement for own funds and Eligible Liabilities (MREL)), es necesario seguir fortaleciendo la solvencia.

La imagen internacional actual del sector bancario español ha mejorado enormemente y está alejada por completo de las sospechas que despiertan otros sectores bancarios como es el caso de Italia, Portugal y Alemania. En el primer caso, la elevada morosidad ha obligado a capitalizar algunos bancos y a crear un «banco malo», estando en el aire el instrumento que se utilizará para rescatar a los bancos. En el segundo, el principal banco del país ha tenido que ser rescatado. Y en el caso de Alemania, las sospechas en torno a una parte del sector (las cajas de ahorros) siempre han flotado en el aire, a lo que ahora se añade una inyección de capital de 8.000 millones de euros, en marzo de 2017, al principal banco del país.

En resumen, la reestructuración del sector bancario español ha dado sus frutos, pero el entorno «hostil» que se ha configurado recientemente plantea un escenario en el que no es nada fácil aumentar la rentabilidad para situarla por encima del coste de captar capital. Paradójicamente tenemos la banca más capitalizada de la historia y, sin embargo, el inversor no ha reducido la prima de riesgo que exige para invertir en banca. La respuesta a esta paradoja es que el inversor descuenta que la rentabilidad seguirá siendo reducida en los próximos años, y de ahí la prima de riesgo que exige. Malos tiempos para la banca, en los que además la imagen y reputación del sector ha salido muy mal parada por distintos motivos (malas prácticas en la comercialización de algunos productos bancarios, cláusulas suelo poco transparentes, etc.), lo que en nada ayuda a la recuperación del sector.

\section{Referencias bibliográficas}

[1] BANCO CENTRAL EUROPEO (2016). «Recent trends in Euroarea banks' business models and implication for banking sector stability». Financial Stability Review, special features, mayo.

[2] BANCO DE ESPAÑA (2016). Informe de Estabilidad Financiera, noviembre. 
[3] COMISIÓN EUROPEA (2017). Informe sobre España 2017, con un examen exhaustivo relativo a la prevención y corrección de los desequilibrios macroeconómicos. COM (2017) 90, final.

[4] CRUZ-GARCÍA, P.; FERNÁNDEZ DE GUEVARA, J. y MAUDOS, J. (2017). «Interest rates and net interest margins: the impact of monetary policy», en G. Chesini, E. Giaretta y A. Paltrinieri (eds.), The Business of Banking: Models, Risk and Regulation. Basingstoke (Reino Unido): Palgrave Macmillan.

[5] FONDO MONETARIO INTERNACIONAL (2016). Global Financial Stability Report, octubre.

[6] MAUDOS, J. (2016). «Márgenes bancarios y tipos de interés: España en el contexto de la Euroárea». Cuadernos de Información Económica, 255, 21-34.

[7] MAUDOS, J. y VIVES, X. (2016). «Banking in Spain», en T. Beck y B. Casu (eds.), Handbook of European Banking, Palgrave MacMillan.

[8] MAUDOS, J. (2017). «Modelos de negocio en la banca europea: cambios recientes». Cuadernos de Información Económica, 257, 11-25. 